\title{
Effect of dietary vitamin A on Senegalese sole (Solea senegalensis) skeletogenesis and larval quality
}

\author{
Ignacio Fernández ${ }^{\mathrm{a}}$, Marta S. Pimentel ${ }^{\mathrm{a}}$, Juan B. Ortiz-Delgado ${ }^{\mathrm{b}}$, Francisco Hontoria ${ }^{\mathrm{c}}$, \\ Carmen Sarasquete ${ }^{\mathrm{d}}$, Alicia Estévez ${ }^{\mathrm{a}}$, Jose Luis Zambonino-Infante ${ }^{\mathrm{e}}$ and Enric Gisbert ${ }^{\mathrm{a}}{ }^{,}$
}

\footnotetext{
a IRTA, Centre d'Aqüicultura, Crta. de Poblenou km 5.5, 43540 Sant Carles de la Ràpita, Tarragona, Spain

b IFAPA-Centro el Toruño, CAP Junta de Andalucía, Ctra. N-IV, 11500 El Puerto de Santa María, Cádiz, Spain

c Instituto de Acuicultura de Torre de la Sal (CSIC), 12595 Torre de la Sal, Castellón, Spain

d Andalusian Institute of Marine Sciences (CSIC), Campus Universitario Rio San Pedro, Apdo. Oficial, 11510 Puerto Real, Cádiz, Spain

e Ifremer, UMR 1067 Nutrition Aquaculture et Génomique des Poissons, Ifremer Centre de Brest, BP 70, 29280

Plouzané, France
}

\author{
*: Corresponding author : Enric Gisbert, Tel.: +34 977745427; fax: +34 977443138, email address : \\ Enric.Gisbert@irta.cat
}

\begin{abstract}
:
The effects of different levels of vitamin A (VA) in Senegalese sole larval performance and development were evaluated by means of a dietary dose-response experiment using enriched Artemia metanauplii as a carrier of this micronutrient. Larvae were fed from 6 to 27 days post hatch (dph) with enriched Artemia containing graded levels of total VA (1.3, 2.1, 4.5 and $12.9 \mu \mathrm{g} V A \mathrm{mg}^{-1}$ DW). The content of VA in live prey directly affected its accumulation in larvae and early juveniles. Retinyl palmitate accumulated during larval ontogeny, whereas retinol showed the opposite trend, decreasing from hatching until $41 \mathrm{dph}$ and then remaining constant until the end of the study.

In metamorphic larvae (10 and $15 \mathrm{dph}$ ), VA did not affect the number of thyroid follicles or the intensity of the immunoreactive staining of $T_{3}$ and $T_{4}$. However, at older stages of development (postmetamorphic larvae: 20, 30, 41 and $48 \mathrm{dph}$ ), VA decreased the number of thyroid follicles but increased their mean size and enhanced $T_{3}$ and $T_{4}$ immunoreactive staining. A dietary excess of VA did not affect either larval performance in terms of growth and survival or the maturation of the digestive system. However, the most remarkable impact of this morphogenetic nutrient was detected during skeletal morphogenesis. Dietary VA accelerated the intramembranous ossification of vertebral centrums, which led to the formation of a supranumerary haemal vertebra and a high incidence of fused and compressed vertebrae in fish fed 2.1, 4.5 and $12.9 \mathrm{mg} \mathrm{VA} \mathrm{mg}^{-1} \mathrm{DW}$. In addition, VA also affected those structures from vertebrae and caudal fin formed by chondral ossification, leading to defects in their shape and fusions with adjacent skeletal elements. In particular, the caudal fin was the region most affected by the dietary treatments. In order of importance, the bones with more developmental anomalies were the modified neural and haemal spines, epural, hypurals and parahypural. The impact of systemic factors such as thyroidal hormones in skeletogenesis should not be neglected since present results revealed that an excess of dietary VA affected the levels of $T_{3}$ and $\mathrm{T}_{4}$, which might have affected bone formation and remodelling, leading to skeletal deformities.
\end{abstract}


Key words: Senegalese sole; Solea senegalensis; larval quality; vitamin A; skeleton; thyroid hormones; deformities.

60

\section{Introduction}

63 Since the nineties, Senegalese sole (Solea senegalensis Kaup, 1858) has been

64 considered a promising flatfish species for diversifying European marine aquaculture

65 (Dinis et al., 1999). Recently, as profit margins for the two main cultured Southern

66 European fish species, gilthead sea bream and European sea bass, have decreased due to their overproduction, interest has increased in Senegalese sole farming in Mediterranean and Southern Atlantic waters. Some of the advantages of culturing Senegalese sole include its high market price, the natural spawning of wild broodstocks held in captivity and mass production of offspring, the rapid development of eggs and larvae, and the high growth rate exhibited by juveniles (see review in Dinis et al., 1999). However, several bottlenecks compromise the intensive culture of this flatfish species, such as the reproduction of F1 broodstock (Anguis and Cañavate, 2005), pathological outbreaks (Zarza et al., 2003), and the production of juveniles in proper quantity and quality to satisfy market demands (high incidence of pigmentary disorders and skeletal deformities) (Soares et al., 2002; Gavaia et al., 2002).

Skeletal deformities and pigmentary disorders are important factors affecting flatfish production costs and determining the fish external morphology, appearance, growth, survival rate, and final market price (Takeuchi et al., 1998; Gavaia et al., 2002; Hamre et al., 2005). The development of these abnormalities is linked to a poorly understood relationship between nutritional, environmental, and genetic factors. Among them, larval nutrition at first feeding is one of the key parameters that affect skeletogenesis and pigmentation processes during early development. In this regard, several studies have shown that nutrients are responsible for the appearance of 
skeletal deformities and pigmentation disorders when their level and/or form of supply in the diet are inappropriate or unbalanced (see review in Lall and Lewis-McCrea, 2007; Hamre et al., 2005). Several authors have indicated that colour abnormalities in Japanese flounder could be effectively reduced by feeding larvae with high doses of vitamin A (VA) (Estévez and Kanazawa, 1995; Dedi et al., 1997; Takeuchi et al., 1995; Haga et al., 2002; Tarui et al., 2006). However, larvae fed high levels of VA showed a high incidence of skeletal deformities (Estévez and Kanazawa, 1995; Dedi et al., 1997; Takeuchi et al., 1998; Martínez et al., 2007) due to the morphogenetic action of this nutrient, which is known to have teratogenic effects in vertebrates at inappropriate dietary levels (Ross et al., 2000). Thus, in a situation in which a given nutrient exerts positive and negative effects simultaneously on different quality parameters, it is very important to determine a safe level that assures a normal skeletal development (minimum incidence of skeletal deformities) while preventing pigmentary disorders (pseudoalbinism and/or ambicolouration). The rapid physiological changes that Senegalese sole larvae undergo throughout development, reaching a fully metamorphosed morphology at an age of 20 days at $20^{\circ} \mathrm{C}$ (Fernández-Díaz et al., 2001), make this species of particular interest for studying the dietary effects of vitamin A on skeletogenesis and metamorphosis.

The objective of the present study was to evaluate the effect of graded levels of dietary VA administered to Senegalese sole larvae during the Artemia feeding phase on larval performance (growth, survival, maturation of the digestive function, and metamorphosis success) and quality (incidence and typology of skeletal deformities).

\section{Materials and methods}

\section{$110 \quad 2.1$ Larval rearing and experimental diets}

111 Newly hatched larvae of Senegalese sole were obtained from Stolt Sea Farm SA

112 (Cambre, La Coruña, Spain) and shipped by road to IRTA facilities. After their 
113 acclimation, larvae were distributed (initial density: 50 larvae $\mathrm{I}^{-1}$ ) in 12 cylindrical tanks

114 (100 I) connected to a recirculation unit (Carbó et al., 2003). Water conditions were as

115 follows: $18 \pm 1^{\circ} \mathrm{C}, 35$ ppt salinity, $\mathrm{pH}$ between $7.8-8.2$, and daily exchange of water

$116(20 \%)$ in the recirculation system with gentle aeration and oxygenation $\left(>4 \mathrm{mg}^{-1}\right)$.

117 Photoperiod was 12L:12D, and light intensity was 500 lux at water surface.

118 Figure 1 shows the feeding protocol for Solea senegalensis used in the present

119 study. In detail, larvae were fed from day 3 post hatch (dph) to $10 \mathrm{dph}$ with rotifers

120 (Brachionus plicatilis) enriched with Easy Selco ${ }^{\text {TM }}$ (ES, INVE, Belgium) following

121 manufacturer's instructions. Rotifer density was 10 rotifers $\mathrm{ml}^{-1}$ from 3 to $4 \mathrm{dph}$ and

122 gradually reduced to 5 rotifers $\mathrm{ml}^{-1}$ at $10 \mathrm{dph}$. Rotifer density was adjusted twice a day

123 in order to assure the optimal prey density. Enriched Artemia metanauplii (EG, INVE,

124 Belgium) were offered to larvae from 6 to $37 \mathrm{dph}$ at increasing densities from 0.5 to 12

125 metanauplii $\mathrm{ml}^{-1}$. Artemia metanauplii density was adjusted four times per day (at 9, 12,

12615 and $18 \mathrm{~h}$ ) to assure the optimal prey density and nutritional VA value; adjustments

127 were conducted according to Cañavate et al. (2006). The retention of VA in enriched

128 Artemia metanauplii in larval rearing tanks during the first four hours of starvation post-

129 enrichment did not change (Fernández, unpublished data). From 33 dph to the end of

130 the experiment (48 dph), larvae were progressively weaned onto dry feed (Gemma

131 Micro $150-300^{\circ}$ Skretting, Spain).

132 The effect of VA in Senegalese sole skeletogenesis was evaluated by means of

133 four different dietary regimes containing graded levels of VA and using enriched

134 Artemia metanauplii as carrier; each regime was done in triplicate. As live preys

135 (rotifers and Artemia nauplii) accumulate VA in different patterns (Giménez et al.,

136 2007), we could not maintain the same levels of VA during the whole live prey-feeding

137 period. Thus, we decided to focus our study only during the Artemia-feeding phase.

138 The graded levels of VA in Artemia metanauplii were obtained by adding different

139 amounts of retinyl palmitate $\left(1,600,000 \mathrm{IU} \mathrm{g}^{-1}\right.$, Sigma-Aldrich, Spain) to a commercial

140 enriching emulsion, Easy Selco ${ }^{\mathrm{TM}}$. Experimental emulsions were designed to contain 
141500 (D1), 1,000 (D2), 2,100 (D3) and 4,000 (D4) retinol equivalents $\mathrm{g}^{-1}$ (Table 1). For

142 comparative purposes, the emulsion containing 500 retinol equivalents $\mathrm{g}^{-1}(1,666 \mathrm{IU} \mathrm{VA}$

$143 \mathrm{~g}^{-1}$ ) was considered as the control group (ES without retinyl palmitate). Both live preys

144 were enriched as previously described in Fernández et al. (2008).

145 Different parameters were measured in order to evaluate the effects of increasing

146 dietary VA levels on larval performance: retinoid content in enrichment emulsions, live

147 prey and larvae; larval growth (in length and weight) and survival rate; metamorphosis

148 (eye migration), bottom settlement and thyroid gland development (size and number of

149 follicles); maturation of the digestive system; and incidence of pigmentation disorders

150 and skeletal deformities. Larvae were sampled and sacrificed with an overdose of

151 anaesthetic (Tricaine methanesulfonate, MS-222, Sigma) at different ages from 2 to 48

$152 \mathrm{dph}$, depending on the parameter considered.

1542.2 Biochemical analysis

155 The retinoid content of the enrichment emulsions, enriched Artemia metanauplii, and

156 larvae was analyzed by HPLC, using a modified version of the method by Takeuchi et

157 al. (1998). After sampling, live prey and larvae were washed with distilled water to

158 remove salt and bacteria, and the samples were frozen at $-80^{\circ} \mathrm{C}$ until posterior

159 analysis. Lipids were extracted with chloroform:methanol (C:M, 2:1) according to

160 Folch's method (Folch et al., 1957) and stored in C:M:BHT (2:1:0.01\%) at $20 \mathrm{mg} \mathrm{l}^{-1}$ and

$161-20^{\circ} \mathrm{C}$ until analysis. Lipid extracts were then evaporated and redissolved in

162 methanol:acetone (1:1, v/v) prior to HPLC analysis. The HPLC system (Thermo

163 Separation Products, San Jose, CA, USA) was equipped with a Lichrospher C-18

164 reversed-phase column (Merck, Darmstadt, Germany) and a UV-visible detector set at

165 a wavelength of $325 \mathrm{~nm}$. The mobile phase was a mixture $(85: 15, \mathrm{v} / \mathrm{v})$ of methanol

166 (98\%) with 0.5\% ammonium acetate and chloroform. The flow rate was $1.5 \mathrm{ml} \mathrm{min}{ }^{-1}$,

167 and the elution time was $18 \mathrm{~min}$. The concentration of each retinoid was calculated

168 from calibration curves constructed with the peak area ratios of their external standards 
and an internal standard of retinol acetate added to the samples. All the reference

170 retinoids were purchased from Sigma-Aldrich (Spain).

171 The specificity of the method for the different retinoid compounds is guaranteed

172 by the retention times of the peaks in the standard injections and the lack of interfering

173 peaks in the blank runs. The four point linear regressions of the peak area and the

174 concentration ratios of the internal standard and each retinoid analysed had $r^{2}$ higher

175 than 0.9886 , and were considered linear in the range of the tested samples. The

176 repeatability was assessed through the injection of five different standard solutions with

177 a mixture of the retinoids analysed for each of the four levels used in the calibration

178 curves. The coefficient of variation was in all cases below 5\%. These standard

179 analyses also allowed checking the \% recovery of the assayed retinoids, which was

180 found between 92 and 101\%. No peak was considered below a signal/noise ratio of 10 .

\subsection{Larval growth and survival rate}

At $2,5,10,15,20,31,41$ and $48 \mathrm{dph}$, fifteen larvae from each tank were randomly sampled, rinsed with distilled water, and used for body size and dry weight determination. Larval standard length (SL) was measured with a digital camera connected to a binocular microscope Nikon SMZ 800 and an image analysis system

188 (AnalySIS, Soft Imaging Systems, GmbH). Once larvae were measured in length, they

189 were dried at $60^{\circ} \mathrm{C}$ until their weight was constant. Samples were weighed with an

190 analytic microbalance (Sartorius BP211D). Survival rate was calculated as the percentage of final surviving fish with respect to the initial number at the beginning of the trial minus those individuals removed for sampling.

\subsection{Maturation of the digestive system}

195 The specific enzyme activity of two intestinal brush border enzymes (alkaline

196 phosphatase and aminopeptidase) and two pancreatic enzymes (trypsin and amylase) 
197 was used to assess the degree of development and maturation of the digestive system

198 of larvae fed graded levels of VA. Enzyme activity was measured at 15, 31, 41 and 48

199 dph (sampling size was 40, 30, 15 and 10 individuals per tank, respectively).

200 Sampled fish were washed with distilled water and stored at $-80^{\circ} \mathrm{C}$ prior to 201 enzyme activity analysis. All fish were dissected to separate pancreatic and intestinal

202 segments as described by Cahu and Zambonino-Infante (1994). Samples were

203 homogenized (Ultra-Turrax D25 basic, IKA ${ }^{\odot}$ - Werke) in five volumes ( $\left./ / \mathrm{w}\right)$ of ice-cold

204 Milli-Q water and centrifuged at 3,300 $\mathrm{g}(3 \mathrm{~min})$ at $4{ }^{\circ} \mathrm{C}$, and the supernatant was

205 removed for pancreatic enzyme quantification. Intestinal brush border membranes for

206 determination of intestinal enzymes were purified according to Crane et al. (1979).

207 Trypsin (E.C. 3.4.21.4) activity was assayed at $25^{\circ} \mathrm{C}$ using BAPNA (N- $\alpha-$

208 benzoyl-DL-arginine $p$-nitroanilide) as substrate (Holm et al., 1988). Amylase (E.C.

209 3.2.1.1) activity was measured using soluble starch (0.3\%) dissolved in $\mathrm{Na}_{2} \mathrm{HPO}_{4}$ buffer

210 pH 7.4 as substrate (Métais and Bieth, 1968). Alkaline phosphatase (E.C. 3.1.3.1) was

211 quantified at $37^{\circ} \mathrm{C}$ using 4-nitrophenyl phosphate (PNPP) as substrate (Bessey et al.,

212 1946). Aminopeptidase N (E.C.3.4.11.2) was determined at $25^{\circ} \mathrm{C}$ according to Maroux

213 et al. (1973) using sodium phosphate buffer $80 \mathrm{mM}(\mathrm{pH}=7.0)$ and L-leucine $p$ -

214 nitroanilide as substrate (in $0.1 \mathrm{mM}$ DMSO). Enzymatic activities were expressed as

215 specific enzyme activity, in milliunits per milligram of protein ( $\mathrm{mU} / \mathrm{mg}$ protein), and

216 soluble protein of crude enzyme extracts was quantified by means of the Bradford's

217 method (Bradford, 1976) using bovine serum albumin as standard. All the assays were

218 conducted in triplicate.

219

2.5 Metamorphosis and bottom settlement

221 Metamorphosis and settlement are two separate processes in flatfish development that

222 might coincide in time depending on the species (Geffen et al., 2007). Thus, we used

223 the term metamorphosis to define morphological and physiological development and

224 the term settlement to define behavioural changes associated with the transition of 
225 larvae from a planktonic to a benthonic way of life. Eye migration in Senegalese sole

226 larvae is generally used as a measure of their metamorphosis progress. In this study,

227 eye migration was evaluated at $10,19,20$ and $30 \mathrm{dph}(n=200$ larvae per dietary

228 treatment) as in Fernández-Díaz et al. (2001). Data are presented as the relative

229 amount of larvae at each stage of development at the same age. At the same sampling

230 dates, digital photographs of the rearing tanks were taken in order to count the amount

231 of swimming larvae in the water column and those at the bottom of the tank using

232 image analysis software (AnalySIS).

233 The development of the thyroid gland (number and size of follicles) was

234 evaluated in samples of $10,15,20,30,41$ and 48 dph larvae $(n=10$ larvae per rearing

235 tank; $n=30$ per dietary treatment). For histological purposes, larvae were processed

236 according to standard histomorphological methods and stained with haematoxylin-

237 eosin. Detection and semiquantification of thyroidal hormones, thyroxin $\left(T_{4}\right)$ and

238 triiodothyronine $\left(\mathrm{T}_{3}\right)$, was conducted according to Ortiz Delgado et al. (2006). At the

239 end of the trial, three hundred and fifty specimens from each tank were examined to

240 evaluate the effect of VA on juvenile pigmentation. Pigmentation in the ocular side was

241 visually assessed by means of individual examination of all specimens, and pigmentary

242 disorders were categorized according to the twelve categories described by Haga et al.

243 (2002).

2.6 Skeletal deformities analysis, observations and measurements

246 To identify and quantify the skeletal deformities of larvae from the different dietary

247 treatments, 50-60 larvae per tank were sampled at the end of the experiment and fixed

248 in formaldehyde solution (10\%) until double stained. Animals were stained for bone and

249 cartilage in whole mount preparations using a modification of the method described by

250 Klymkowsky and Hanken (1991).

251 After staining, fish were placed on their blind (left) side to observe meristic

252 characters and skeletal abnormalities in the cranium, vertebral column, and caudal fin 
complex. Skeletal structures were identified and named according to Gavaia et al.

254 (2002) and Wagemans and Vandewale (2001). The study focused on the mean number of vertebrae and the frequency of individuals with an abnormal number of vertebrae. Special attention was given to the deformities occurring in the cranial region, vertebral column, and caudal fin complex (hypurals, parahypural, epural, modified haemal spines and modified neural spine).

\subsection{Statistical analysis}

261 Results are given as mean and standard deviation. Data expressed as percentage

262 (survival, incidence of skeletal deformities, eye migration success, pigmentary disorders, and larval bottom settlement) were previously $\arcsin \left(x^{1 / 2}\right)$-transformed. All data were checked for normality (Kolmogorov-Smirnov test) and homoscedasticity of variance (Bartlett's test) and then compared by means of One Way ANOVA (Zar, 1974). When significant differences were detected, the Tukey multiple-comparison test was used to detect differences among experimental groups. Correlation between different variables was evaluated with the Pearson Product Moment Correlation test. In all statistical analyses, the level of significant difference was set at $P<0.05$. All the statistical analyses were conducted using SigmaStat 3.0 (Systat Software Inc.,

271 Richmond, USA).

\section{Results}

\subsection{Retinoid content in experimental emulsions and live prey}

277 Table 1 presents the total lipid and total VA content (retinol and retinyl palmitate) in

278 experimental emulsions used for enriching Artemia metanauplii with graded levels of

279 retinyl palmitate. No statistically significant differences were detected in the total lipid

280 content of experimental emulsions containing different levels of VA (ANOVA, $P>0.05$ ). 
281 Total VA content in the emulsions increased with increasing levels of retinyl palmitate

282 incorporated (ANOVA, $P<0.05)$

283 The retinoid content and total VA of enriched Artemia metanauplii is shown in

284 Figure 2. The HPLC analysis revealed that the main retinoid found in enriched Artemia 285 was retinyl palmitate (VA ester), representing between 67 to $76 \%$ of the total VA

286 content. The retinyl palmitate concentration increased in enriched Artemia with

287 increasing levels of this compound in the enriching emulsion (ANOVA, $P<0.05$ ). The

288 level of retinyl palmitate in live prey increased up to 5.1 times when we compared

289 Artemia enriched with D1 and D4 (7.7 and $39.4 \mathrm{ng} \mathrm{mg}^{-1} \mathrm{DW}$, respectively). The content

290 of retinol (VA alcohol) in enriched live prey followed a similar pattern. While the retinol

291 content of Artemia enriched with D1 and D2 was not significantly different, its level

292 increased from 3.4 to $15.3 \mathrm{ng} \mathrm{mg}^{-1} \mathrm{DW}(4.5$-fold increase) (ANOVA, $P<0.05)$ in D1-

293 and D4-enriched Artemia, respectively. In contrast, the retinoic acid content in Artemia

294 enriched with D4 was 16.8 times higher than in Artemia enriched with D1 and D2, in

295 which it increased from 0.37 to $6.2 \mathrm{ng} \mathrm{mg}^{-1} \mathrm{DW}$, respectively. Artemia enriched with D3

296 showed intermediate levels of retinoic acid accumulation (1.0 $\mathrm{ng} \mathrm{mg}^{-1} \mathrm{DW}$; 2.8 -fold

297 increase in relation to the control group) (ANOVA, $P<0.05$ ). Retinal (aldehyde form of

298 VA) was not detected in Artemia enriched with graded levels of VA.

$300 \quad 3.2$ Retinoid content in larvae

301 Figure 3 shows the retinoid (retinol and retinyl palmitate) content in Senegalese sole

302 larvae fed different VA regimes between 2 and $48 \mathrm{dph}$. During the study, retinyl

303 palmitate increased as a consequence of the level of this retinoid in Artemia, whereas

304 retinol showed the opposite trend and decreased to $55 \%$ as compared to its content in

305 2-dph larvae.

306 At the end of the study, the accumulation of retinyl palmitate and retinol in early

307 juveniles was linked to the level of total VA administered during the Artemia feeding

308 phase $\left(r^{2}=0.97\right.$ and 0.99, respectively; $P<0.001$, Pearson Product Moment 
309 Correlation test). However, only the values of retinyl palmitate and retinol body content

310 in fish fed D4-enriched Artemia were significantly higher than the mean value from the

311 rest of dietary groups $\left(27.75 \pm 2.68 v s .22 .61 \pm 0.25 \mathrm{ng}\right.$ retinyl palmitate $\mathrm{mg}^{-1} \mathrm{DW}$ and

$3120.88 \pm 0.07$ vs. $0.70 \pm 0.03$ ng retinol $\mathrm{mg}^{-1} \mathrm{DW} ; P<0.05$, ANOVA).

\section{3.3 Larval growth and survival}

315 At $10 \mathrm{dph}$, larvae fed D1-, D2-, and D3-enriched Artemia were significantly larger than

316 larvae fed the diet containing the highest content of total VA (D4) (Fig. 4a; ANOVA, $P<$

317 0.05). However, no differences in larval size were detected at older ages (15, 20 and

$31831 \mathrm{dph}$ ) until 41 and $48 \mathrm{dph}$, coinciding with the weaning phase. At 41 and $48 \mathrm{dph}$, fish

319 fed Artemia enriched with the control emulsion (D1) were larger than those from the

320 rest of the dietary groups (Table 2; ANOVA, $P<0.05$ ). Dry weight was not significantly

321 affected by any of the dietary treatments at any sampling time of the experiment (Fig.

$3224 \mathrm{~b}$; ANOVA, $P>0.05)$. Different levels of total VA in enriched Artemia did not affect

323 Senegalese sole larval survival at the end of the study (Table 2; ANOVA, $P>0.05$ ).

\subsection{Maturation of the digestive system}

326 Figure 5 shows changes in the enzyme specific activity of selected pancreatic and

327 intestinal enzymes from fish fed the control diet (D1). From 15 to $48 \mathrm{dph}$, the specific

328 activity of amylase gradually decreased from 0.619 to $0.014 \cup \mathrm{mg}$ protein $^{-1}$ (ANOVA, $P$

$329<0.05)$. A 2.8-fold decrease in trypsin specific activity was also observed between 15

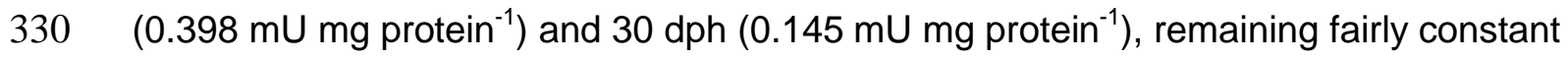

331 until the end of the study. However, alkaline phosphatase specific activity was constant

332 from 15 to $41 \mathrm{dph}\left(4.02 \mathrm{U} \mathrm{mg}_{\text {protein }}{ }^{-1}\right)$ but showed a 2.2-fold increase at $48 \mathrm{dph}$ (8.86

$333 \mathrm{U} \mathrm{mg}_{\text {protein }}{ }^{-1}$ ). In contrast, aminopeptidase-N specific activity remained constant

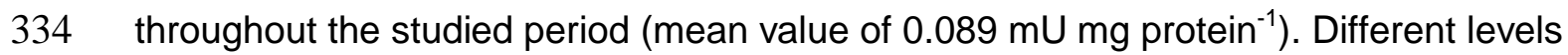

335 of VA did not affect the specific activity of pancreatic or intestinal enzymes at any

336 sampling point considered (ANOVA, $P>0.05$ ). At 41 and $48 \mathrm{dph}$, trypsin, alkaline 
337 phosphatase and aminopeptidase-N specific activity tended to be lower in fish fed D3

338 and D4 in comparison to fish fed D1 and D2, although this reduction in enzyme activity

339 was not statistically significant (data not shown).

\subsection{Metamorphosis and bottom settlement}

342 Results of thyroid gland development are presented in Table 3. In 10- and 15-dph

343 metamorphic larvae, dietary VA levels affected the number of thyroid follicles, although

344 not significantly (ANOVA, $P>0.05$ ). The intensity of the immunoreactive staining of $T_{3}$

345 and $\mathrm{T}_{4}$ hormones showed no differences between the above-mentioned larval ages

346 (Table 4). At older stages of development (20, 30, 41 and 48 dph post-metamorphic

347 larvae), the increase in dietary VA reduced the number of follicles while increasing their

348 average size (ANOVA, $P<0.05$ ). These changes in the development of the thyroid

349 glands concurred with an increase in the immunoreactive staining of $T_{3}$ and $T_{4}$

350 hormones (Fig. 6).

$351 \quad$ Bottom settlement was a fast process in Senegalese sole larvae that coincided

352 with metamorphosis (eye migration). At $20 \mathrm{dph}$ all fish had settled to the bottom, and

353 most of them had completed eye migration. The level of VA in enriched Artemia did

354 only significantly affect the process of settlement in metamorphosing larvae at $9 \mathrm{dph}$,

355 when fish fed D3 and D4 showed higher rates of benthic larvae (8.6 $\pm 2.9 \%)$ in

356 contrast to those from D1 and D2 groups (6.1 $\pm 1.8 \%)$ (ANOVA, $P<0.05)$. No

357 significant differences in the rate of benthic larvae were detected at older ages among

358 different experimental groups (12 dph: $66.0 \pm 8.8 \%$; $14 \mathrm{dph}: 89.5 \pm 4.0 \%$; $19 \mathrm{dph}: 96.4$

$359 \pm 1.4 \%$; $20 \mathrm{dph}: 100 \%$; data shown as the mean value of all experimental groups). Eye

360 migration results are shown in Figure 7. The onset of eye migration started earlier in

361 fish fed D2, D3 and D4 than in the control group. At $10 \mathrm{dph}$, the D2, D3, and D4 groups

362 showed a higher frequency of specimens in stage 1 than the control group (23.8 vs.

$3632.2 \%$, respectively; ANOVA, $P<0.05)$. However, these differences were not evident at

364 older ages (19, 20 and $30 \mathrm{dph})$. Also, no differences in the frequency of fish at further 
stages of eye migration (stages 2-4) were detected among different dietary

completed (stage 4) and any case of abnormal eye migration was recorded in any of the experimental groups.

At the end of the study, the rate of fish exhibiting pigmentation problems was the same for all the dietary groups (ANOVA, $P>0.05$ ), with an average incidence of pseudoalbinism of $2.3 \pm 1.0 \%$. Ambicolouration was not observed in any of the sampled fish fed different levels of VA.

\subsection{Skeletal deformities: typology and frequencies}

Dietary levels of VA directly affected skeletogenesis and the incidence of skeletal deformities in Senegalese sole (Figure 8a). The frequency of deformed specimens increased with the dietary dose of VA, as well as the incidence of fish with more than one deformity in their skeleton (ANOVA, $P<0.05$ ). In particular, the incidence of deformities ranged from fish with only one small skeletal abnormality to fish displaying multiple deformities with different degrees of severity (Fig. 8b; Fig. 11). structures mostly affected were those related with the opercular complex, especially the preopercular, interopercular, ceratohyal, and ceratobranchials 1-5. The incidence of cranial deformities in the D4 group was significantly correlated to the presence of deformed prehaemal vertebrae numbers 1-3 $\left(r^{2}=0.998, P=0.002\right)$. No skeletal deformities were observed in the jaw apparatus and neurocranium in any of the dietary treatments.

The vertebral column was composed of 45 vertebrae, divided in 8 prehaemal and 37 haemal vertebrae (including the urostyle). No significant differences were

390 detected in the mean number of specimens with 44,45 and 46 vertebrae (ANOVA, $P>$

391 0.05) among the different VA treatments. However, the incidence of a supranumerary 
392 vertebra was higher in fish fed D2, D3 and D4 than in those fed D1 (36.0, 38.0 and

39344.4 vs. $28.0 \%$, respectively; $P=0.02$ ).

394 Figure 9 shows the incidence of deformities along the vertebral column axis. In

395 all experimental groups, most of deformities affecting the axial skeleton where

396 observed between the vertebra number 38 and the urostyle; whereas increasing

397 dietary levels of VA increased the incidence of deformities in the prehaemal vertebrae.

398 Skeletal abnormalities in the vertebral column (prehaemal and haemal regions)

399 increased with increasing levels of dietary VA in enriched Artemia $\left(r^{2}=0.981, P=\right.$

$400 \quad$ 0.018; Fig. 10a). Torsion of the first three prehaemal (cephalic) vertebrae (14\%) was

401 recorded only in fish fed the highest dose of VA (D4). This type of deformity consisted

402 of a change in the morphology of the vertebral disk resulting in a realignment of the

403 axial skeleton and a slight torsion of the basioccypital articulatory process (Fig. 11b).

404 The frequencies of deformities in prehaemal and haemal vertebral centrums (fusion

405 and compression) were significantly affected by the level of VA in the diet (Fig. 10b, c),

406 although prehaemal centrums were less affected than haemal ones (16.7 vs. $63.3 \%$ in

407 fish fed D1). No significant differences were detected in the incidence of deformities

408 affecting the prehaemal centrums among fish fed D1, D2 and D3 diets (18.4\%;

409 ANOVA, $P>0.05$ ), whereas the incidence of deformities in haemal vertebrae

410 significantly increased with the level of dietary VA (ANOVA, $P<0.05$ ). However, the

411 frequency of fish with abnormal prehaemal and haemal centrums significantly

412 increased $3.2(59.3 \%)$ and 1.5 times (97.3\%), respectively, in fish fed D4 (ANOVA, $P<$

413 0.05), indicating that prehaemal centrums were more sensitive than haemal centrums

414 to dietary levels of VA.

415 Vitamin A also significantly affected the incidence of deformed neural and

416 haemal spines (Fig. 10d and e; ANOVA $P<0.05$ ). Figures 11c and 11d show different

417 typologies of deformities affecting vertebral spines. The frequency of both abnormal

418 neural spines and haemal spines was similar between fish fed D1 and D2 (78.4 and

$41971.4 \%$, respectively), whereas it progressively increased in fish fed D3 (86.7 and 80.7, 
respectively) and D4 diets (98.7 and 92.7\%, respectively), showing significant differences (ANOVA, $P<0.05$ ). The incidence of deformed parapophyses increased from $19.3 \%$ in fish fed D1 up to $50.7 \%$ in fish fed D4 (2.6-fold increase; Fig. 10f), whereas those specimens fed D2 and D3 showed intermediate values of abnormal parapophyses (35.0\%).

The dietary VA level affected all the skeletal structures composing the caudal fin complex, although the incidence of deformities varied depending on the structure considered and the dose of VA (Fig. 12a). The most common deformity affecting the parahypural and the hypurals (1-5) was the fusion of these structures with those adjacent, which produced changes in their regular shape (Fig. 11e-h). The occurrence of abnormal hypurals increased with high levels of dietary VA. The incidence of fish with abnormal hypurals almost doubled, from $36.7 \%$ in fish fed D1 up to $66.0 \%$ in those fed D4. Fish fed D2 and D3 showed intermediate values of abnormal hypurals (48.7\%), with no significant differences between them (ANOVA $P<0.05$; Fig. 12c). The incidence of abnormal parahypural was similar among fish fed Artemia enriched with D1, D2, and D3 (13.3\% average value for the three treatments), which was significantly lower than in fish in the D4 group (41.3\%; Fig. 12b; ANOVA, $P<0.05)$. The incidence of deformed (twisted) epural in fish fed D2 and D3 (31.0\%) showed a 1.9-fold increase in relation to fish from the control group (16.0\%), whereas this rise was 3.7 times higher in fish fed D4 (58.7\%; Fig. 12d). No significant differences were detected in the incidence of deformities affecting the modified neural spine between D1, D2, and D3 groups (40.4\%; ANOVA, $P>0.05$ ), whereas in the D4 group the number of fish with abnormal modified neural spine significantly increased 1.7 times (68.0\%; Fig. 12e; ANOVA, $P<0.05)$. The frequency of abnormal modified haemal spines $(1-2)$ tended to

444 increase with increasing levels of dietary VA (Fig. 12f), being 2.3 times higher in fish

445 fed D4 than in those fed D1. A significant increase of 1.4- and 1.9-fold was recorded in 446 fish fed D2 and D3, respectively (ANOVA $P<0.05$ ). 


\section{Discussion}

451 The effects of different levels of VA in Senegalese sole larval development were studied by means of a dose-response experiment using enriched Artemia metanauplii as carrier. Although the use of microdiets in co-feeding rearing protocols for the early weaning of Senegalese sole has been greatly improved (Fernández-Díaz et al., 2006; Engrola et al., 2009), we decided to bioencapsulate VA in live prey because Senegalese sole larvae cannot be fed exclusively with microdiets. As previously shown (Giménez et al., 2007), total VA in Artemia metanauplii accumulated proportionally to the content of retinyl palmitate in the enriching emulsions. Although retinoic acid was absent in the original emulsion, its presence in the metanauplii enriched with the highest levels of VA (D3 and D4) indicated that live prey were able to metabolize different retinoids and oxidize retinol into retinoic acid. Since retinoic acid is a much more active VA metabolite than the other retinoids (Ross et al., 2000), interpreting the results from the dose-response experiment must take into consideration its presence in D3- and D4-enriched Artemia metanauplii. The retinoid content in live prey directly affected the accumulation of VA in the larvae and, especially, in early juveniles, as retinyl palmitate and retinol body contents clearly showed. Of the two forms of VA, retinyl palmitate was the dominant form accumulated in Senegalese sole tissues. Under our experimental conditions, retinyl palmitate accumulated during larval ontogeny, whereas retinol showed the opposite trend, decreasing from hatching until $41 \mathrm{dph}$ and then remaining constant until the end of the study. Retinyl esters, the main form of retinoids in live prey, are hydrolyzed into retinol in the lumen of the larval

472 digestive tract, absorbed by the enterocytes, re-esterified, and transported to the liver 473 through the lymphatic system by chylomicrons. Once in the liver, the main site for VA 474 body storage, retinyl esters are hydrolyzed and re-esterified again in retinyl palmitate, 475 which is finally stored in hepatocytes (Hamre et al., 2005). Thus, the accumulation of 
retinyl palmitate in Senegalese sole larvae would reflect the dose-dependent

477 accumulation of this form of VA due to the experimental feeding treatments and the

478 larval age. In contrast, ontogenetic changes in both VA metabolism and larval

479 requirements might explain the decrease in retinol content during the experimental

480 period, since this form of VA and retinal constitute the total VA content in eggs and

481 newly hatched larvae, with their content decreasing with larval development and

482 metamorphosis (Moren et al., 2004a).

483 In fish species, VA requirements for normal development and optimal growth present

484 inter-specific differences. Thus, in Japanese flounder (Dedi et al. 1997; Haga et al.

485 2003), Atlantic salmon (Ørnsrud et al. 2002), European sea bass (Villeneuve et al.,

4862005,2006 ), red sea bream (Hernández et al., 2006), and gilthead sea bream

487 (Fernández et al., 2008), high dietary doses of VA during larval development lead to

488 poor growth performance and survival. Surprisingly, we found that Senegalese sole

489 larval survival and growth, in terms of body weight, were not affected by the dietary VA

490 content, and differences in total length were only observed after the weaning.

491 Therefore, high levels of VA were not toxic (hypervitaminosis A) in terms of final growth

492 in weight and survival of the fish, and the smaller size of the fish might be a

493 consequence of a higher incidence of deformities in the caudal region of their vertebral

494 column (Haga et al., 2002). According to the National Research Council, the

495 requirements of VA for juveniles of different fish species, such as rainbow trout,

496 salmon, channel catfish and sea bream, ranged between 1,000 and 3,500 IU kg ${ }^{-1}$

497 (NRC, 1993). In contrast, when considering different flatfish species, the safe level of

498 VA in Artemia nauplii for preventing the development of skeletal abnormalities in

499 Japanese flounder was less than 45,200 IU VA kg ${ }^{-1}$ (Dedi et al., 1995). In summer

500 flounder and Atlantic halibut juveniles fed microdiets containing different levels of VA, a

501 diet containing less than 52,873 and 8,333 $\mathrm{IU} \mathrm{VA} \mathrm{kg}^{-1}$ respectively has been described

502 as the best for assuring a proper juvenile development (Lewis-McCrea and Lall, 2007;

503 Moren et al., 2004b, respectively). Under present experimental conditions, Senegalese 
504 sole larvae fed Artemia metanauplii enriched with a commercial emulsion containing

$5054,333 \mathrm{IU} \mathrm{kg}^{-1}$ showed a high incidence of skeletal abnormalities, which seems to

506 indicate that this species is quite sensitive to low dietary levels of this nutrient.

507 However, published results regarding the VA requierements in different fish species

508 might be taken cautiously, since there might be differences depending on the stage of

509 development of experimental fish (larva vs. juvenile), the type of retinoid compound

510 included into the diet (retinyl esters, retinoic acid or carotenoids), the experimental

511 design, the rearing conditions or the analytical method for VA quantification.

512 Thyroid hormones, VA, and fatty acids are all factors that have been shown to

513 affect metamorphosis in flatfish by disrupting the normal pigmentation and eye

514 migration patterns (see reviews by Hamre et al., 2005, 2007). Several authors have

515 described hyperpigmentation (Martínez et al., 2002) or improved pigmentation (Estévez

516 and Kanazawa, 1995; Takeuchi et al., 1995; Dedi et al., 1997; Haga et al. 2002) of

517 flatfish larvae fed live prey enriched with VA, although in some studies high VA levels

518 increased the frequency of skeletal deformities. Under the present conditions, dietary

519 VA did not affect pigmentation patterns in Senegalese sole. This might indicate a

520 species-specific sensitivity to a dietary excess of VA in the differentiation of pigmentary

521 cells that may either differentiate into adult melanonophores or disappear by apoptotic

522 processes (see review in Bolker and Hill, 2000).

523 In addition, dietary levels of VA did not alter the process of settlement in

524 metamorphosing Senegalese sole larvae, although they affected eye migration in early

525 metamorphosis (10 dph). Thus, 10-dph larvae fed high levels of VA (D2, D3, and D4

526 groups) showed a precocious formation of the ocular channel and the initiation of eye

527 migration. These differences were not observed in the latter stages. Senegalese sole

528 presents a narrow size threshold for the onset of metamorphosis, resulting in a

529 synchronised settling behaviour and a uniform post-settlement size distribution

530 (Fernández-Diaz et al., 2001). Thus, the high frequency of larvae in early stages of

531 metamorphosis at $10 \mathrm{dph}$ might be associated with their larger size, since 
532 metamorphosis in this species depends on larval size (see review in Geffen et al.,

533 2007) and the levels of thyroid hormones (Ortiz Delgado et al., 2006; Klaren et al., 534 2008).

$535 \quad$ Pancreatic and intestinal enzyme activity provides a reliable marker of larval fish 536 development (Zambonino Infante et al., 2008). In the present study, an excess of 537 dietary VA did not affect the activity levels of these digestive enzymes in Senegalese

538 sole larvae, which followed the general trend previously described for this species

539 (Ribeiro et al., 1999). In contrast, gilthead sea bream (Fernández et al., 2008) and

540 European sea bass (Villeneuve et al., 2005, 2006) larvae fed high doses of VA showed

541 a delay in the maturation of their digestive function. Thus, we can hypothesize that the

542 levels of VA tested in the present experiment are sublethal, since they did not affect the

543 overall development of Senegalese sole larvae, neither in terms of larval survival, body

544 weight, nor maturation of the digestive function. On the other hand, dietary VA levels

545 affected dramatically the normal process of bone formation and skeletogenesis in

546 Senegalese sole larvae.

547 Different studies have shown a high incidence of skeletal deformities in 548 hatchery-reared early juveniles of Senegalese sole, ranging from 44\% (Gavaia et al., 5492002 ) to $80 \%$ (Engrola et al., 2009). In our study, fish fed the control diet also showed a

550 high frequency of individuals with deformed skeletal structures. Furthermore, an

551 increase of dietary VA resulted in a significant increase in deformities. The incidence of

552 skeletal deformities reported in Senegalese sole reared under standard feeding

553 protocols is higher than that observed in other commonly produced species in the

554 Mediterranean area, like gilthead sea bream (Boglione et al., 2001; Fernández et al., 555 2008) or European sea bass (Villeneuve et al., 2005; Mazurais et al., 2008). Two

556 different hypotheses might explain such a high incidence of skeletal deformities in

557 Senegalese sole. The first considers that this flatfish species is more prone to develop

558 skeletal disorders than other fish species under any rearing conditions. The second

559 hypothesis postulates that since the skeletal deformities observed in Senegalese sole 
560 were not lethal, higher final numbers of Senegalese sole specimens with deformities

561 would be observed at the juvenile stage. Consequently, the observed incidence of

562 deformities in Senegalese sole early juveniles was higher than in those species where deformities were lethal at early stages (Divanach et al., 1997; Koumoundouros et al., 1997; Boglione et al., 2001). Since both hypotheses are not mutually exclusive, determining which of the two models better explains the observations requires further developmental studies that would identify the most sensitive periods of morphogenesis and skeletogenesis to the development of deformities, as well as the timing of appearance of the deformities and their impact on larval survival. sole were those from the vertebral column and caudal fin complex. Previously

571 published studies found that several structures from the splanchnocranium, such as the 572 premaxilla, maxilla and dentary bones, were the structures most severely affected by 573 dietary VA (Haga et al., 2002, 2003; Villeneuve et al., 2005, 2006; Fernández et al., 574 2008). However, these skeletal structures did not show any changes in fish fed 575 experimental diets in the present study. Since the diets with VA in excess were not offered to the larvae until $7 \mathrm{dph}$, when most of the pharyngeal skeleton was already ossified, the absence of changes in those skeletal structures is probably related to the

578 timing of VA administration. In the present study, the opercular complex, in particular, 579 the preopercular, interopercular, ceratohyal, and ceratobranchials 1-5, were mostly

580 affected by the diet with the highest level of VA and retinoic acid (D4). The strong 581 statistical correlation (Pearson Product Moment Correlation test) found between the deformed opercular structures and the cephalic vertebrae, suggests that the altered shapes of the opercular bones are a consequence of the torsion of the first three

584 prehaemal (cephalic) vertebrae coupled with the restructuring processes of the cranial 585 bones. These processes take place during eye migration and the completion of the 586 typical asymmetrical body shape of this species; thus, the observed deformities seem 587 to be more related to a disruption (acceleration) of the normal larval metamorphosis 
pattern, rather than dietary VA acting directly on the above-mentioned opercular 589 elements.

$590 \quad$ Vitamin A impaired the development and number of vertebrae in Senegalese

591 sole. Similarly to Japanese flounder (Haga et al., 2002) and gilthead sea bream

592 (Fernández et al., 2008), high levels of dietary VA in Senegalese sole were responsible

593 for a higher incidence of a supranumerary vertebra in the haemal region of the

594 vertebral column of the fish. Contrastingly, in European sea bass an excess of VA

595 resulted in the loss of one vertebra (Villeneuve et al., 2006). In Senegalese sole, since

596 morphogenesis of the vertebral centrums follows a caudal direction (Gavaia et al.,

597 2002), vertebrae from the haemal region are the last ones to differentiate and ossify by

598 intramembranous ossification. The notochord is responsible for the proper

599 morphogenesis of the vertebral centrums, and consequently this tissue plays an

600 important role in inducing vertebral formation and maintaining vertebral morphogenesis

601 (Witten et al., 2005). Thus, dietary VA levels might have disrupted the segmentation of

602 the notochord and the normal process of morphogenesis in the vertebral centrums,

603 leading to a change in the number of vertebrae, as Haga et al. (2009) recently

604 demonstrated using transgenic zebrafish exposed to retinoic acid.

605 The impact of dietary VA on the incidence of skeletal deformities in different

606 regions of the vertebral column was also affected by the timing of the intramembranous

607 ossification. The first three prehaemal (cephalic) vertebrae, which are the first elements

608 of the vertebral column to ossify (Gavaia et al., 2002), were the least affected in

609 comparison to the rest of the prehaemal and haemal regions. Only deformed cephalic

610 vertebrae were detected in fish fed D4-enriched Artemia containing high levels of

611 retinyl palmitate and retinoic acid, whereas deformities affecting the rest of the

612 prehaemal and all the haemal vertebrae were detected in all experimental groups,

613 although at different prevalence rates. Therefore, the dose of VA and the timing of

614 morphogenesis directly affect the incidence of skeletal disorders (Villeneuve et al.,

615 2006; Mazurais et al., 2008). Skeletal deformities affecting prehaemal and haemal 
616 vertebrae in Senegalese sole early juveniles included: compressed, deformed and

617 fussed centrums; alterations of the intervertebral space; and deformed (twisted)

618 parapophyses, neural and haemal spines, which were more frequent in the haemal

619 vertebrae of fish fed high doses of dietary VA. According to Gavaia et al. (2002), who

620 described the osteological development of the caudal complex and vertebral column in

621 Senegalese sole for the first time, the development of both vertebral column and

622 caudal fin complex begins at $12-13 \mathrm{dph}\left(16-18^{\circ} \mathrm{C}\right)$. However, in the present study this

623 development might have occurred earlier due to the slightly higher rearing

624 temperatures. In this regard, the high incidence of deformities in the prehaemal and

625 haemal regions of the vertebral column seemed to be related to an abnormally early

626 differentiation pattern. Thus, a prolonged exposure to an excess of VA might have

627 altered the normal process of morphogenesis in those skeletal elements formed either

628 by chondral (neural and haemal spines) or by intramembranous (vertebral centrums)

629 ossification. This would enhance the appearance of skeletal disorders, as previously

630 described in Japanese flounder (Haga et al., 2002), Atlantic salmon (Ørnsrud et al.,

631 2002), European sea bass (Villeneuve et al., 2005, 2006), red sea bream (Hernández

632 et al., 2006), summer flounder (Martínez et al., 2007), and gilthead sea bream

633 (Fernández et al., 2008). Compressed vertebrae and reductions in the intervertebral

634 spaces might be associated with the presence of supranumerary vertebrae, as

635 reported for gilthead sea bream (Fernández et al., 2008). However, in Senegalese sole

636 the incidence of supranumerary vertebrae was not proportional to that of vertebral

637 compressions and fusions. These findings suggest that these skeletal deformities might

638 also be related to alterations in the areas of vertebral centrum growth and the failure of

639 notochord cells to maintain proper vertebral development and growth, as described in

640 Atlantic salmon (Witten et al., 2005).

641 The caudal fin complex was the most altered region of the Senegalese sole

642 skeleton, although the incidence of deformities varied depending on the structure

643 considered and the dose of VA. Although the deformities affected all the skeletal 
644 elements composing the caudal fin, the most affected structures, in order of

645 importance, were the modified neural and haemal spines, epural, hypurals, and

646 parahypural. These results are in agreement with those observed in Japanese flounder

647 (Dedi et al., 1998) but differ from those reported in gilthead sea bream fed an excess of

648 VA, where the most affected caudal bones were the epurals, hypurals, parahypural,

649 neural arch, and uroneurals (Fernández et al., 2008). The differences between both

650 flatfish species and gilthead sea bream might be due to species-specific patterns in the

651 morphogenesis of the caudal complex linked to metamorphosis and the acquisition of

652 asymmetry and benthic life. Considering previous descriptions of the osteological

653 development of the caudal fin complex (Gavaia et al., 1999; 2006) and the results

654 obtained in Japanese flounder and gilthead sea bream larvae fed graded levels of VA

655 (Dedi et al., 1998; Fernández et al., 2008, respectively), the differences in sensitivity to

656 dietary VA amongst caudal fin skeletal elements might be due to differences in their

657 ontogenetic development and the duration of VA exposure. The high incidence of

658 fusion between hypurals and parahypural has also been observed in Japanese

659 flounder early juveniles (Dedi et al., 1998). Thus, VA might have stimulated the

660 differentiation and proliferation of chondrocytes (hypertrophic differentiation) in the

661 above-mentioned structures, leading to their fusion due to their close proximity and

662 their almost simultaneous temporal development (Gavaia et al., 2002).

663 Up to this point, we have only considered the effect of VA on Senegalese sole

664 skeletogenesis by its direct action through retinoic acid in the skeletal tissue. However,

665 present results indicate that $\mathrm{VA}$ also affected the levels of thyroid hormones $\mathrm{T}_{3}$ and $\mathrm{T}_{4}$

666 in Senegalese sole larvae. Thyroid hormones are essential regulators of skeletal

667 development and bone maintenance (Wexler and Sharretts, 2007). During

668 development, thyroid hormones, especially $T_{3}$, are essential for the recruitment and

669 maturation of bone cells. In mammals, alterations in the thyroid status result in

670 acceleration of bone formation (by either chondral or intramembranous ossification),

671 growth abnormalities, bone loss, and increased fracture risk (Harvey et al., 2002). In 
672 particular, excessive amounts of thyroid hormone induce increased activity of

673 osteoblasts and osteoclasts leading to high bone turnover and loss of bone mineral

674 density, as the activity of osteoclasts predominates over the activity of osteoblasts

675 (Mikosch, 2005). The action of thyroid hormones on the development and health of the

676 skeletal tissue is mediated by nuclear receptor proteins (TR), which are expressed in

677 chondrocytes and osteoblasts. These proteins are members of the superfamily of

678 hormone and orphan nuclear receptors and function as hormone-inducible transcription

679 factors (Harvey et al., 2002). The TR proteins together with retinoid $X$ receptors form

680 heterodimers $(R X R)$ that bind to specific $T_{3}$-response element sequences within target

681 gene promoters and modulate their transcriptional regulation (Duncan Basset et al., 682 2007). Thus, there is a convergence of VA- and thyroid hormone receptor-mediated 683 pathways on bone formation and remodelling. Although Senegalese sole has an

684 acellular bone, the mechanisms of bone tissue formation and growth are quite 685 conserved among vertebrates and also their signalling pathways (Witten and 686 Huysseune, 2007), which implies that modifications in the thyroid hormone status might 687 have a direct effect on skeletal morphogenesis. Disruption of these pathways by either 688 dietary VA imbalances or changes in the levels of $T_{3}$ might affect the process of normal 689 skeletogenesis, leading to skeletal deformities.

\section{5. Conclusions}

693

694 Under the present experimental conditions and independently of the feeding treatment, 695 Senegalese sole exhibited high levels of skeletal abnormalities, particularly in the 696 vertebrae and caudal fin complex. Therefore, even the control group (fish fed Artemia 697 metanauplii enriched with a commercial emulsion) was exposed to a dietary dose of VA 698 that might have altered the harmonious development of the axial and caudal skeleton. 699 Thus, we need to conduct further research using emulsions with even lower levels of 
700 VA (retinyl palmitate) to discriminate between the effects of this nutrient and other

701 factors inducing skeletal disorders in Senegalese sole. In this regard, we need to

702 evaluate the effect of other nutrients, such as essential fatty acids, minerals and

703 vitamins (particularly liposoluble vitamins D, E, and K) (Lewis et al., 2007; Mazurais et

704 al., 2008), genetic factors (Kacem et al., 2004), and/or unsuitable husbandry and

705 rearing practices and rearing temperatures (Lewis et al., 2004; Blanksma et al., 2009;

706 Sfakianakis et al., 2006), that might also have been affecting the skeletal development

707 of Senegalese sole larvae. The inherent complexity of skeletogenesis is such that a

708 holistic approach to discriminate and evaluate the relative importance of each of the

709 above-mentioned factors is not possible, and consequently this question needs to be

710 addressed in singular experiments.

711 Our studies on the effects of different dietary VA levels on Senegalese sole

712 performance revealed that an excess of VA affected neither larval performance in

713 terms of survival and growth nor the maturation of the digestive system. However, this

714 morphogenetic nutrient had a remarkable impact in the skeleton morphogenesis. An

715 excess of VA accelerated the intramembranous ossification of vertebral centrums,

716 leading to a supranumerary haemal vertebra and a high incidence of fused and

717 compressed vertebrae. In addition, VA also affected those structures from the

718 vertebrae and caudal fin formed by chondral ossification, leading to defects in their

719 shape and fusions with adjacent skeletal elements. However, we should not dismiss

720 the impact of other systemic factors such as thyroidal hormones in skeletogenesis

721 since in our studies an excess of dietary VA affected the levels of thyroid hormones $\left(T_{3}\right.$

722 and $\mathrm{T}_{4}$ ), which might have affected metamorphosis, bone formation and remodelling,

723 leading to skeletal deformities.

724 Further studies are needed to identify the potential crosstalk between VA and thyroid

725 hormones and their effects on the expression of different genes involved in Senegalese

726 sole early morphogenesis and skeletogenesis.

727 


\section{Acknowledgments}

730 The authors would like to express their gratitude to J. Canoura, M. Monllaó, and N.

731 Gras for their excellent technical assistance with live prey rearing and biochemical analyses. We thank Stolt Sea Farm for their generosity in supplying fish. This work was

733 funded by the Ministry of Education and Culture (MEC) of the Spanish Government

734 (project AGL2005-02478). I.F was supported by a predoctoral MEC fellowship and E.G.

735 and J.B. O-D. by the Programa Ramón y Cajal (MEC, Spain).

736

737

738

\section{References}

739

Anguis, V., Cañavate, J.P., 2005. Spawning of captive Senegal sole (Solea senegalensis) under a naturally fluctuating temperature regime. Aquaculture 243,

Bessey, O.A., Lowry, O.H., Brock, M.J., 1946. Rapid coloric method for determination of alkaline phosphatase in five cubic millimeters of serum. J. Biol. Chem. 164,

Boglione, C., Gagliardi, F., Scardi, M., Cataudella, S., 2001. Skeletal descriptors and quality assessment in larvae and post-larvae of wild-caught and hatchery-reared gilthead sea bream (Sparus aurata L. 1758). Aquaculture 192, 1-22.

Bolker, J.A., Hill, C.R., 2000. Pigmentation development in hatchery-reared flatfishes. J. Fish Biol. 56, 1029-1052. 72, 248-254. 
754 Cahu, C., Zambonino-Infante, J.L., 1994. Early weaning of sea bass Dicentrarchus labrax larvae with a compound diet: effect on digestive enzymes. Comp. Biochem. Physiol. 109A, 213-222.

Cañavate, J.P., Zerolo, R., Fernández-Díaz, C., 2006. Feeding and development of Senegal sole (Solea senegalensis) larvae reared in different photoperiods. Aquaculture 258, 368-377.

Carbó, R., Estévez, A., Furones, M.D., 2003. Intelligent and multifunctional recirculation system. Its application in research at CA-IRTA. Spec. Publ.-EAS 32, 171-172.

Crane, R.K., Boge, G., Rigal, A., 1979. Isolation of brush border membranes in vesicular form from the intestinal spiral valve of the small dogfish Scyliorhinus canicula. Biochim. Biophys. Acta 554, 264-267.

Dedi, J., Takeuchi, T., Seikai, T., Watanabe, T., 1995. Hypervitaminosis and safe levels of vitamin A for larval flounder (Paralichthys olivaceus) fed Artemia nauplii.

Dedi, J., Takeuchi, T., Seikai, T., Watanabe, T., Hosaya, K., 1997. Hypervitaminosis A during vertebral morphogenesis in larval Japanese flounder. Fish. Sci. 63, 466473.

Dedi, J., Takeuchi, T., Hosoya, K., Watanabe, T., Seikai, T., 1998. Effect of vitamin A levels in Artemia nauplii on the caudal skeleton formation of Japanese flounder

Dinis, M.T., Ribeiro, L., Soares, F., Sarasquete, M.C., 1999. A review on the cultivation

Divanach, P., Papandroulakis, N., Anastasiadis, P., Koumoundouros, G., Kentouri, M., 1997. Effect of water currents on the development of skeletal deformities in sea bass (Dicentrarchus labrax) with functional swim bladder during postlarval and nursery phase. Aquaculture 156, 145-155. 
780 Duncan Bassett, J.H., Nordström, K., Boyde, A., Howell, P.G.T., Kelly, S., Vennström, 781 B., Williams, G.R., 2007. Thyroid status during skeletal development determines 782 adult bone structure and mineralization. Mol. Endocrinol. 21, 1893-1904.

783 Engrola, S., Figueira, L., Conceição, L.E.C., Gavaia, P. J., Ribeiro, L., Dinis, M.T., 2009. Co-feeding in Senegalese sole larvae with inert diet from mouth opening promotes growth at weaning. Aquaculture, 288, 264-27.

Estévez, A., Kanazawa, A., 1995. Effect of (n-3) PUFA and vitamin A Artemia enrichment on pigmentation success of turbot, Scophthalmus maximus. Aquacult. Nutr. 1, 159-168.

Estévez, A., Kanazawa, A., 1996. Fatty acid composition of neural tissues of normally pigmented and unpigmented juveniles of Japanese flounder using rotifer and Artemia enriched in n-3 HUFA. Fish. Sci. 62, 88-93.

Fernández-Díaz, C., Yúfera, M., Cañavate, J.P., Moyano, F.J., Alarcón, F.J., Díaz, M. 2001. Growth and physiological changes during metamorphosis of Senegal sole reared in the laboratory. J. Fish Biol. 58, 1086-1097.

Fernández-Díaz, C., Kopecka, J., Cañavate, J.P., Sarasquete, C., Solé, M., 2006. Variations on development and stress defences in Solea senegalensis larvae fed on live and microencapsulated diets. Aquaculture 251, 573-584.

Fernández, I., Hontoria, F., Ortiz-Delgado, J.B., Kotzamanis, Y., Estévez, A., Zambonino-Infante, J.L., Gisbert, E., 2008. Larval performance and skeletal purification of total lipids from animal tissues. J. Biol. Chem. 226, 497-509.

804 Gavaia, P.J., Sarasquete, C., Cancela, M.L., 1999. Detection of mineralized structures 805 in early stages of development of marine teleostei using a modified alcian blue806 alizarin red double staining technique Biotechnic and Histochemistry 75, 89-94. 
Gavaia, P.J., Dinis, M.T., Cancela, M.L., 2002. Osteological development and abnormalities of the vertebral column and caudal skeleton in larval and juvenile stages of hatchery-reared Senegal sole (Solea senegalensis). Aquaculture 211,

Gavaia, P.J., Simes, D.C., Ortiz-Delgado, J.B., Viegas, C.S.B., Pinto, J.P., Kelsh, R.N., Sarasquete, M.C., Cancela, M.L., 2006. Osteocalcin and matrix Gla protein in zebrafish (Danio rerio) and Senegal sole (Solea senegalensis): Comparative gene and protein expression during larval development through adulthood. Gene Expr. Patterns 6, 637-652.

Geffen, A.J., van der Veer, H.W., Nash, R.D.M., 2007. The cost of metamorphosis in flatfishes. J. Sea Res. 58, 35-45.

Giménez, G., Kotzamanis, Y., Hontoria, F., Estévez, A., Gisbert, E., 2007. Modelling retinoid content in live prey: a tool for evaluating the nutritional requirements and development studies in fish larvae. Aquaculture 267, 76-82.

Haga, Y., Takeuchi, T., Seikai, T., 2002. Influence of all-trans retinoic acid on pigmentation and skeletal formation in larval Japanese flounder. Fish. Sci. 68, 560-570.

Haga, Y., Suzuki, T., Kagechika, H., Takeuchi, T., 2003. A retinoic acid receptorselective agonist causes jaw deformity in the Japanese flounder, Paralichthys

830 Hamre, K., Moren, M., Solbakken, J., Opstad, I., Pittmann, K., 2005. The impact of 831 nutrition on metamorphosis in Atlantic halibut (Hippoglossus hippoglossus L.). $832 \quad$ Aquaculture, 250, 555-565. 
833 Hamre, K., Holen, E., Moren, M., 2007. Pigmentation and eye migration in Atlantic

834 halibut (Hippoglossus hippoglossus L.) larvae: new findings and hypotheses.

$835 \quad$ Aquac. Nutr. 13, 65-80.

836 Harvey, C.B., O'Shea, P.J., Scott, A.J., Robson, H., Siebler, T., Shalet, S.M., Samarut,

837 J., Chassande, O., Williams, G.R., 2002. Molecular mechanisms of thyroid

838 hormone effects on bone growth and function. Mol. Genet. Metabol. 75, 17-30

839 Hernández, L.H., Teshima, S., Koshio, S., Ishikawa, M., Gallardo-Cigarroa, F.J., Alam,

840 M.S., Uyan, O., 2006. Effects of vitamin A palmitate, beta-carotene and retinoic

841 acid on the growth and incidence of deformities in larvae of red sea bream

$842 \quad$ Chrysophrys major. Cienc. Mar. 32, 195-204.

843 Holm, H., Hanssen, L.E., Krogdahl, A., Florholmen, J., 1988. High and low inhibitor

844 soybean meals affect human duodenal proteinase activity differently: in vivo

845 comparison with bovine serum albumin. J. Nutr. 118, 515-520.

846 Kacem, A., Meunier, F.J., Aubin, J., Haffray, P., 2004. Caractérisation histo-

847 morphologique des malformations du squelette vertébral chez la truite arc-en-ciel

848 (Oncorhynchus mykiss) après différents traitements de triploidisation. Cybium 28,

$849 \quad 15-23$.

850 Klaren, P.H.M., Wunderink, Y.S., Yúfera, M., Mancera, J.M., Flik, G., 2008. The thyroid

851 gland and thyroid hormones in Senegalese sole (Solea senegalensis) during

852 early development and metamorphosis. Gen. Comp. Endocrinol. 155, 686-694.

853 Klymkowsky, M.W., Hanken, J., 1991. Whole mount staining of Xenopus and other

854 vertebrates. Methods Cell Biol. 36, 419-411.

855 Koumoundouros, G., Gagliardi, F., Divanach, P., Boglione, C., Cataudella, S., Kentouri, 856 M., 1997. Normal and abnormal osteological development of caudal fin in Sparus $857 \quad$ aurata L. fry. Aquaculture 149, 215-226.

858 Lall, S.P., Lewis-McCrea, L., 2007. Role of nutrients in skeletal metabolism and 859 pathology in fish, an overview. Aquaculture 267, 3-19. 
860 Maroux, S., Louvard, D., Baratti, J., 1973. The aminopeptidase from hog intestinal $861 \quad$ brush border. Biochim. Biophys. Acta 321, 282-295

862 Martinez, G.M., Baron, M.P., Bolker, J.A., 2007. Skeletal and pigmentation defects 863 following retinoic acid exposure in larval summer flounder, Paralichthys dentatus. $864 \quad$ J. World Aquac. Soc. 38, 353-366.

865 Mazurais, D., Darias, M.J., Gouillou-Coustans, M.F., Le Gall, M.M., Huelvan, C., 866 Desbruyères, E., Quazuguel, P., Cahu, C., Zambonino-Infante, J.L., 2008. Dietary 867 vitamin mix levels influence the ossification process in European sea bass 868 (Dicentrarchus labrax) larvae. Am. J. Physiol. Regul. Integr. Comp. Physiol. 294, 869 $520-527$.

Métais, P., Bieth, J., 1968. Détermination de l'a-amylase par une microtechnique. Ann. Biol. Clin. 26, 133-142.

Mikosch, P., 2005. Effects of thyroid disorders on the bone. Wien. Med. Wochenschr. $155,444-453$.

Moren, M., Opstad, I., Hamre, K., 2004a. A comparison of retinol, retinal and retinyl ester concentrations in larvae of Atlantic halibut (Hippolglossus hippoglossus L.) fed Artemia or zooplankton. Aquac. Nutr. 10, 253- 259.

Moren, M., Opstad, I., Berntssen, M.H.G., Zambonino Infante, J.L., Hamre, K., 2004b. An optimum level of vitamin A supplements for Atlantic halibut (Hipoglossus in first-feeding fry of the Atlantic salmon (Salmo salar L.). Aquacult. Nutr. 8, 7-13.

882 Ortiz Delgado, J.B., Ruane, N.M., Pousão-Ferreira, P., Dinis, M.T., Sarasquete, C., 883 2006. Thyroid gland development in Senegalese sole (Solea senegalensis Kaup 884 1858) during early life stages: A histochemical and immunohistochemical $885 \quad$ approach. Aquaculture 260, 346-356 
886 Ribeiro, L., Zambonino-Infante, J.L., Cahu, C., Dinis, M.T., 1999. Development of 887 digestive enzymes in larvae of Solea senegalensis, Kaup 1858. Aquaculture 179, $888 \quad 465-473$.

889 Ross, S.A., Caffery, P.J., Draguer, U.C., De Luca, L.M., 2000. Retinoids in embryonal 890 development. Physiol. Rev. 80, 1021-1054.

891 Soares, F., Engrola, S., Dinis, M.T., 2002. Anomalías en la pigmentación de juveniles 892 de lenguado (Solea senegalensis). Bol. Inst. Esp. Oceanogr. 18, 405-407.

893 Sfakianakis, D.G., Georgakopoulou, G., Papadakis, I.E., Divanach, P., Kentouri, M., 894 Koumoundouros, G., 2006. Environmental determinants of haemal lordosis in $895 \quad$ European sea bass, Dicentrarchus labrax (Linnaeus, 1758). Aquaculture 254, 54896 64.

897 Takeuchi, T., Dedi, J., Ebisawa, C., Watanabe, T., Seikai, T., Hosoya, K., Nakazoe, 898 J.I., 1995. The effect of betacarotene and vitamin A enriched Artemia nauplii on 899 the malformation and color abnormality of larval Japanese flounder. Fish. Sci. 61, $900 \quad 141-148$.

901 Takeuchi, T., Dedi, J., Haga, Y., Seikai, T., Watanabe, T.1998. Effect of vitamin A 902 compounds on bone deformity in larval Japanese flounder (Paralichthys 903 olivaceus). Aquaculture 169, 155-165.

904 Tarui, F., Haga, Y., Ohta, K., Shima, Y., Takeuchi, T., 2006. Effect of Artemia nauplii 905 enriched with vitamin palmitate on hypermelanosis on the blind side in juvenile 906 Japanese flounder Paralichthys olivaceus. Fish. Sci. 72, 256-262.

907 Villeneuve, L., Gisbert, E., Le Delliou, H., Cahu, C.L., Zambonino-Infante, J.L., 2005.

908 Dietary levels of all-trans retinol affect retinoid nuclear receptor expression and 909 skeletal development in European sea bass larvae. Br. J. Nutr. 93, 1-12.

910 Villeneuve, L., Gisbert, E., Moriceau, J., Cahu, C.L., Zambonino Infante, J.L., 2006.

911 Intake of high levels of vitamin A and polyunsaturated fatty acids during different 912 developmental periods modifies the expression of morphogenesis genes in

913 European sea bass (Dicentrarchus labrax). Br. J. Nutr. 95, 677-687. 
914 Wagemans, F., Vandewalle, P., 2001. Development of the bony skull in common sole:

915 brief survey of morpho-functional aspects of ossification sequence. J Fish Biol.

$916 \quad 59,1350-1369$.

917 Wexler, J.A., Sharretts, J., 2007. Thyroid and Bone. Endocrinol. Metab. Clin. N. Am.

$918 \quad 36,673-705$.

919 Witten, P.E., Gil-Martens, L., Hall, B.K., Huysseune, A., Obach, A., 2005. Compressed

920 vertebrae in Atlantic salmon Salmo salar. evidence for metaplastic

921 chondrogenesis as a skeletogenic response late in ontogeny. Dis. Aquat. Org.

$922 \quad 64,237-246$.

923 Witten, P.E., Huysseune, A., 2007. Mechanisms of chondrogenesis and osteogenesis

924 in fins. In: Hall, B.K. (Ed.), Fins and Limbs; Development, Evolution and

925 Transformation. Chicago University Press, Chicago, 79-92.

926 Zambonino-Infante, J., Gisbert, E., Sarasquete, C., Navarro, I., Gutiérrez, J., Cahu,

927 C.L., 2008. Ontogeny and physiology of the digestive system of marine fish

928 larvae. In: Feeding and digestive functions of fish. Cyrino J.E.O., Bureau D. and

929 Kapoor B.G. (eds). Science Publishers. Inc, Enfield, USA pp 277-344.

930 Zar, J.H., 1974. Biostatistical Analysis. Prentice Hall, Englewood Cliffs, NJ. USA.

931 Zarza, C., Padrós, F., Estévez, A., Crespo, S., Furones, M.D., 2003. New fish species

932 for aquaculture, old pathological problems: the case of Solea sp. Proc. 11th

$933 \quad$ European Assoc. Fish Pathologist, St Julians, Malta.

934 


\section{Figure captions}

936 Figure 1. Feeding protocol of Senegalese sole. Artemia metanauplii were enriched with

937 experimental emulsions containing 500 (D1), 1,000 (D2), 2,100 (D3) and 4,000 (D4)

938 retinol equivalents $\mathrm{g}^{-1}$.

939

940 Figure 2. Retinoid (retinoic acid, retinol, and retinyl palmitate) and total vitamin A

941 content (ng retinoid compound $\mathrm{mg}^{-1} \mathrm{DW}$ ) in Artemia metanauplii enriched with graded

942 levels of VA [500 (D1), 1,000 (D2), 2,100 (D3) and 4,000 (D4) retinol equivalents $\mathrm{g}^{-1}$ ].

943 For comparative purposes, the mean value of the total VA content in enriched live prey

944 is included for each treatment. Different letters denote the existence of statistically

945 significant differences among the content of different compounds depending on the

946 treatment (ANOVA, $P<0.05)$.

947

948 Figure 3. Changes in body content of retinol and retinyl palmitate (ng retinyl palmitate

$949 \mathrm{mg} \mathrm{DW}^{-1}$ ) of Senegalese sole larvae fed graded levels of vitamin A. Different indexed

950 letters show significant differences between treatments (ANOVA, $P<0.05$ ).

951

952 Figure 4. Growth in standard length (a) and dry weight (b) of Senegalese sole larvae

953 fed Artemia enriched with graded levels of VA. At $10 \mathrm{dph}$, the asterisk denotes the

954 existence of significant differences in standard length between groups (see text for

955 details). The dotted line represents the onset of the weaning period. Different letters

956 indicate statistically significant differences among dietary treatments (ANOVA, $P<$

$957 \quad 0.05)$

958

959

960 Figure 5. Changes in specific enzyme activity of trypsin (a), amylase (b), alkaline

961 phosphatase (c), and aminopeptidase-N (d) in Senegalese sole fed the control diet. 
962 Different letters denote the existence of statistically significant differences among

963 different sampling points (ages).

964

965 Figure 6. Immunolocalization of $\mathrm{T}_{3}$ and $\mathrm{T}_{4}$ in Senegalese sole larvae fed different levels 966 of vitamin A (haematoxylin and eosin/peroxidase staining). Thyroid follicles in a 15-dph

967 larva from D1 (a) and D3 (b). Note the presence of a small follicle at the base of the 968 aortic bulb (arrowhead); (c) and (d), thyroid follicles of a 20-dph larva exhibiting a weak $969 \mathrm{~T}_{4}$ immunoreactivity within the colloid (D1 treatment); (e) and (f), thyroid follicles of 30970 dph larvae showing a moderate $T_{3}$ immunostaining (D1 treatment); (g), thyroid follicles 971 of 41-dph larvae showing moderate $T_{3}$ immunoreactivity (D1 treatment). Note the 972 increase of $T_{3}$ staining for the D3 treatment (h). Changes in the thyroid gland 973 development at $48 \mathrm{dph}$ when comparing D1 with D4 treatments: note the decrease in 974 the number of follicles and the increase in their mean size, coupled with an increase of $975 \mathrm{~T}_{4}$ staining intensity on $S$. senegalensis larvae from D4 treatment [(i) and (j), D1; (k) 976 and (I)]. Scale bars represent $100 \mu \mathrm{m}$.

Figure 7. Metamorphosis stages of Senegalese sole larvae fed graded levels of vitamin A. Staging was established according to Fernández-Díaz et al. (2001). Different indexed letters show significant differences among treatments (ANOVA, $P<0.05$ ).

982

983

984 Figure 8. Incidence of skeletal deformities affecting the head, vertebral column, and tail 985 in Senegalese sole fed graded levels of vitamin A (a). Incidence of deformities considering the number of abnormal skeletal elements per fish (b). Cranial deformities in Senegalese sole fed the highest dose of VA showing the most affected skeletal

988 elements of the opercular complex (c). Different indexed letters show significant 989 differences among treatments (ANOVA, $P<0.05$ ). 
992 Figure 9. Incidence of deformities in prehaemal and haemal vertebrae along the 993 vertebral axis in Senegalese sole larvae fed different levels of vitamin A. Feeding 994 treatments: D1 (a), D2 (b), D3 (c), and D4 (d).

995

996 Figure 10. Incidence of skeletal deformities in the vertebral column of Senegalese sole 997 fed graded levels of vitamin A. Total vertebral (prehaemal and haemal) deformities (a), 998 deformed prehaemal (b) and haemal (c) centrums, abnormal neural (d) and haemal (e) 999 spines, and parapophysis (f). Different indexed letters show significant differences 1000 among treatments (ANOVA, $P<0.05$ ).

1001

1002 Figure 11. Examples of different typologies of skeletal deformities found in Senegalese 1003 sole under the present experimental conditions. (a) General view of a 30-dph

1004 metamorphic larva with a severe deformity in the vertebral column. (b) Torsion (T) of 1005 the first three prehaemal (cephalic) vertebrae resulting in deformed preopercular (Po), 1006 interopercular (Io) and ceratohyal (Ch). Note the space between the head and the 1007 abdominal region (arrow) as an indicator of the head's torsion. (c) Ectopical structure 1008 connecting neural spines from two adjacent haemal vertebrae (arrow). (d)

1009 Compression of centrums of haemal vertebrae and haemal vertebra with deformed 1010 haemal prezigapophysis (Hprz) and poszigapophysis (Hpz). (e) Fusion of haemal 1011 vertebrae numbers 43 and 44 with fusion of their respective haemal spines (asterisk).

1012 (f) Deformities affecting the caudal fin: deformed urostyle, fused hypurals 4-3 and 2-1, 1013 and fusion of hypural 1 with the modified haemal spine. (g) Compression of haemal 1014 vertebrae numbers 41-44 and disappearance of the intervertebral space among them.

1015 (h) Fusion of hypurals 1-5 and compression of haemal vertebrae (note the absence of 1016 intervertebral spaces among vertebral centrums). Abbreviations: Ep: epural; Hy: 
1017 hypural; Mhs: modified haemal spine; Mns: modified neural spine; Phy: parahypural;

1018 Ur: urostile.

1019

1020 Figure 12. Incidence of deformities in the caudal fin complex in Senegalese sole fed

1021 graded levels of vitamin A. Percentage of specimens with at least one deformity in the

1022 caudal fin (a), parahypural (b), hypurals (c), epural (d), modified neural spine (e), and

1023 modified haemal spine (f). Different indexed letters show significant differences among

1024 treatments (ANOVA, $P<0.05)$.

1025

1026

1027

1028

1029

1030 
Table 1. Total lipid and retinoid content (retinyl palmitate, retinol and total VA) in experimental Artemia enriching emulsions. Total lipid content is expressed as \% DW and retinoid content in emulsions is expressed as $\mu \mathrm{g} \mathrm{mg}^{-1} \mathrm{DW}$. Different letters within the same column show significant differences between emulsions (ANOVA, $P<0.05$ ).

\begin{tabular}{lcccc}
\hline Emulsion & Total lipids & Retinyl palmitate & Retinol & Total VA \\
\hline D1 & $84.3 \pm 2.94$ & $1.23 \pm 0.010 \mathrm{a}$ & $0.0051 \pm 0.0005 \mathrm{a}$ & $1.32 \pm 0.030 \mathrm{a}$ \\
D2 & $81.7 \pm 3.31$ & $2.07 \pm 0.440 \mathrm{ab}$ & $0.0057 \pm 0.0003 \mathrm{ab}$ & $2.09 \pm 0.123 \mathrm{~b}$ \\
& & & & \\
D3 & $87.8 \pm 6.25$ & $4.47 \pm 0.830 \mathrm{~b}$ & $0.0079 \pm 0.0005 \mathrm{~b}$ & $4.50 \pm 0.249 \mathrm{c}$ \\
& & & & \\
D4 & $82.7 \pm 3.01$ & $12.87 \pm 0.198 \mathrm{c}$ & $0.013 \pm 0.002 \mathrm{c}$ & $12.91 \pm 0.059 \mathrm{~d}$ \\
\hline
\end{tabular}



Table 2. Final larval size in standard length (SL) and dry weight (DW), and survival rate of Senegal sole larvae fed different levels of vitamin A. Values are mean \pm standard deviation. Different letters within the same column show statistical significant differences.

\begin{tabular}{lccc}
\hline Dietary treatment & SL $(\mathbf{m m})$ & DW $(\mathbf{m g})$ & Survival (\%) \\
\hline D1 & $13.35 \pm 0.09 \mathrm{a}$ & $7.42 \pm 0.40$ & $47.1 \pm 4.0$ \\
D2 & $11.91 \pm 0.10 \mathrm{c}$ & $5.29 \pm 0.30$ & $45.6 \pm 2.9$ \\
D3 & $12.40 \pm 0.10 \mathrm{~b}$ & $6.13 \pm 0.29$ & $41.6 \pm 0.7$ \\
D4 & $11.84 \pm 0.10 \mathrm{c}$ & $6.30 \pm 0.40$ & $41.3 \pm 5.1$
\end{tabular}


Table 3. Differences in the number and size of thyriod follicles of Senegal sole larvae fed different levels of vitamina A. Different letters within the same age range (rows) show statistical significant differences among emulsions (ANOVA, $P<0.05)$.

\begin{tabular}{lcccc|cccc}
\hline $\begin{array}{l}\text { Days } \\
\text { post- } \\
\text { hatching }\end{array}$ & \multicolumn{3}{c}{ Number of follicles } & \multicolumn{4}{c}{ Size (mean \pm SD) $\mu \mathrm{m}$} \\
\cline { 2 - 8 } & D1 & D2 & D3 & D4 & D1 & D2 & D3 & D4 \\
\hline $10 \mathrm{dph}$ & 2 & 4 & 5 & 5 & $26.4 \pm 3.21^{\mathrm{a}}$ & $26.0 \pm 8.06^{\mathrm{a}}$ & $25.0 \pm 8.05^{\mathrm{a}}$ & $25.4 \pm 9.49^{\mathrm{a}}$ \\
$15 \mathrm{dph}$ & 4 & 5 & 6 & $6-7$ & $25.7 \pm 9.86^{\mathrm{a}}$ & $21.3 \pm 3.40^{\mathrm{a}}$ & $26.1 \pm 5.45^{\mathrm{a}}$ & $28.3 \pm 8.19^{\mathrm{a}}$ \\
$20 \mathrm{dph}$ & 6 & $2-4$ & 5 & $4-5$ & $41.9 \pm 1.58^{\mathrm{a}}$ & $39.1 \pm 16.01^{\mathrm{a}}$ & $56.7 \pm 5.79^{\mathrm{ab}}$ & $59.5 \pm 2.78^{\mathrm{b}}$ \\
$30 \mathrm{dph}$ & 7 & $3-5$ & $3-4$ & $4-5$ & $75.4 \pm 8.55^{\mathrm{a}}$ & $95.1 \pm 11.06^{\mathrm{a}}$ & $112.2 \pm 2.23^{\mathrm{bc}}$ & $115.4 \pm 3.34^{\mathrm{c}}$ \\
$41 \mathrm{dph}$ & 8 & 5 & $4-5$ & 5 & $81.1 \pm 2.13^{\mathrm{a}}$ & $114.1 \pm 8.89^{\mathrm{b}}$ & $125.1 \pm 9.12^{\mathrm{bc}}$ & $132.2 \pm 8.23^{\mathrm{c}}$ \\
$48 \mathrm{dph}$ & $10-15$ & 6 & $6-7$ & 6 & $88.2 \pm 5.24^{\mathrm{a}}$ & $124.0 \pm 1.33^{\mathrm{b}}$ & $131.1 \pm 5.56^{\mathrm{bc}}$ & $135.1 \pm 6.69^{\mathrm{c}}$ \\
\hline
\end{tabular}


Table 4. Semiquantitative assessment of thyroid hormones content by using immunohistochemical approaches. Asterisks indicate reaction colour intensities: */- weak; * moderate; ** intense; ${ }^{\star \star *}$ very intense.

\begin{tabular}{lcccc|cccc}
\hline Days post- & \multicolumn{4}{c|}{$\mathrm{T}_{3}$ - immunoreactivity } & \multicolumn{4}{c}{$\mathrm{T}_{4}$ - immunoreactivity } \\
\cline { 2 - 8 } hatching & D1 & D2 & D3 & D4 & D1 & D2 & D3 & D4 \\
\hline $10 \mathrm{dph}$ & $* /-$ & $*$ & $*$ & $*$ & $*$ & $*$ & $*$ & $*$ \\
$15 \mathrm{dph}$ & $* /-$ & $* /-$ & $*$ & $*$ & $*$ & $*$ & $*$ & $*$ \\
$20 \mathrm{dph}$ & $*$ & $*$ & $*$ & $*$ & $*$ & $*$ & $*$ & $*$ \\
$30 \mathrm{dph}$ & $*$ & $*$ & $* *$ & $*$ & $*$ & $*$ & $*$ & $*$ \\
$41 \mathrm{dph}$ & $*$ & $*$ & $* *$ & $* *$ & $*$ & $*$ & $*$ & $* * *$ \\
$48 \mathrm{dph}$ & $*$ & $*$ & $* *$ & $* * *$ & $*$ & $*$ & $*$ & $* * *$ \\
\hline
\end{tabular}


Click here to download high resolution image

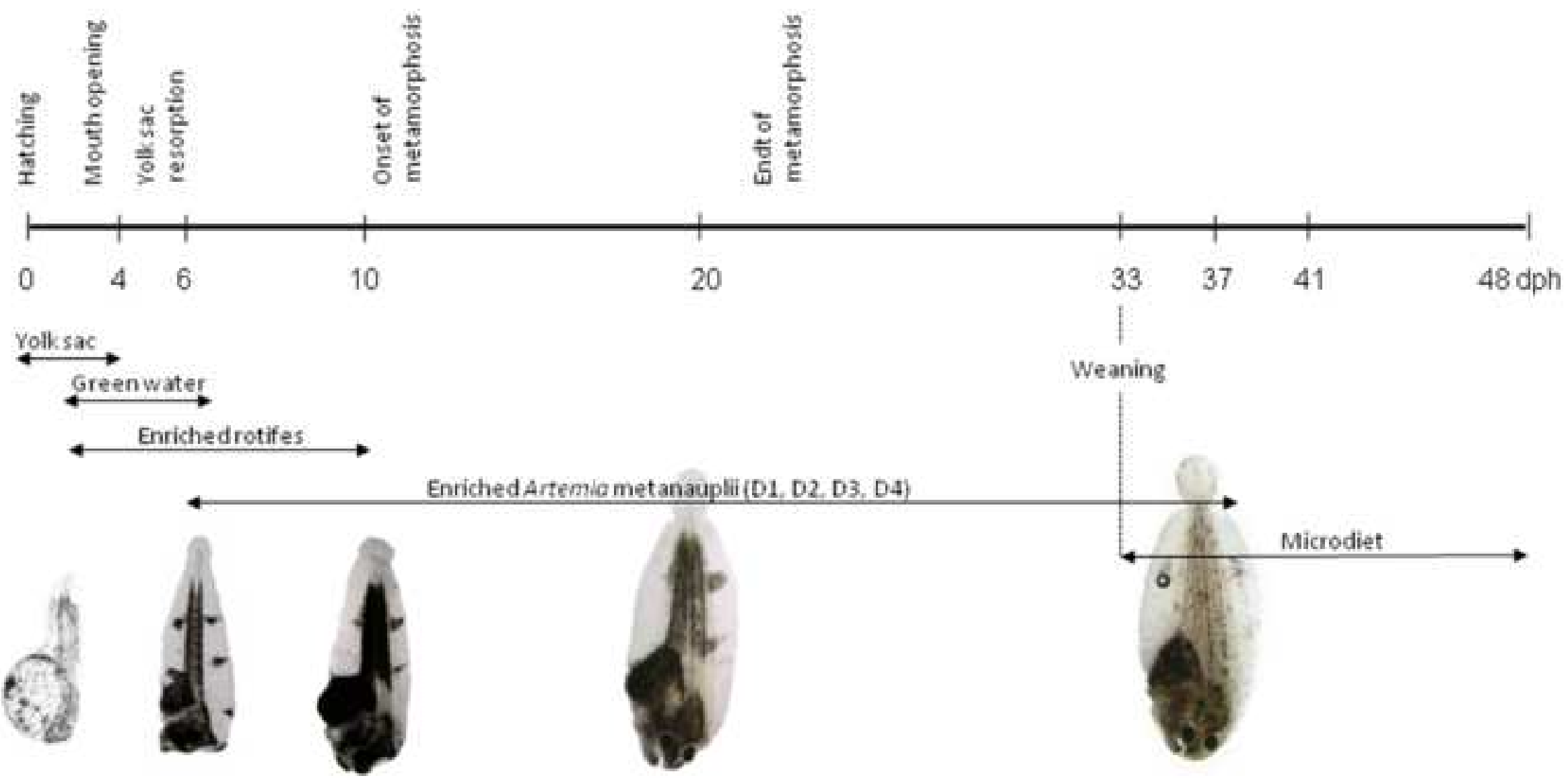




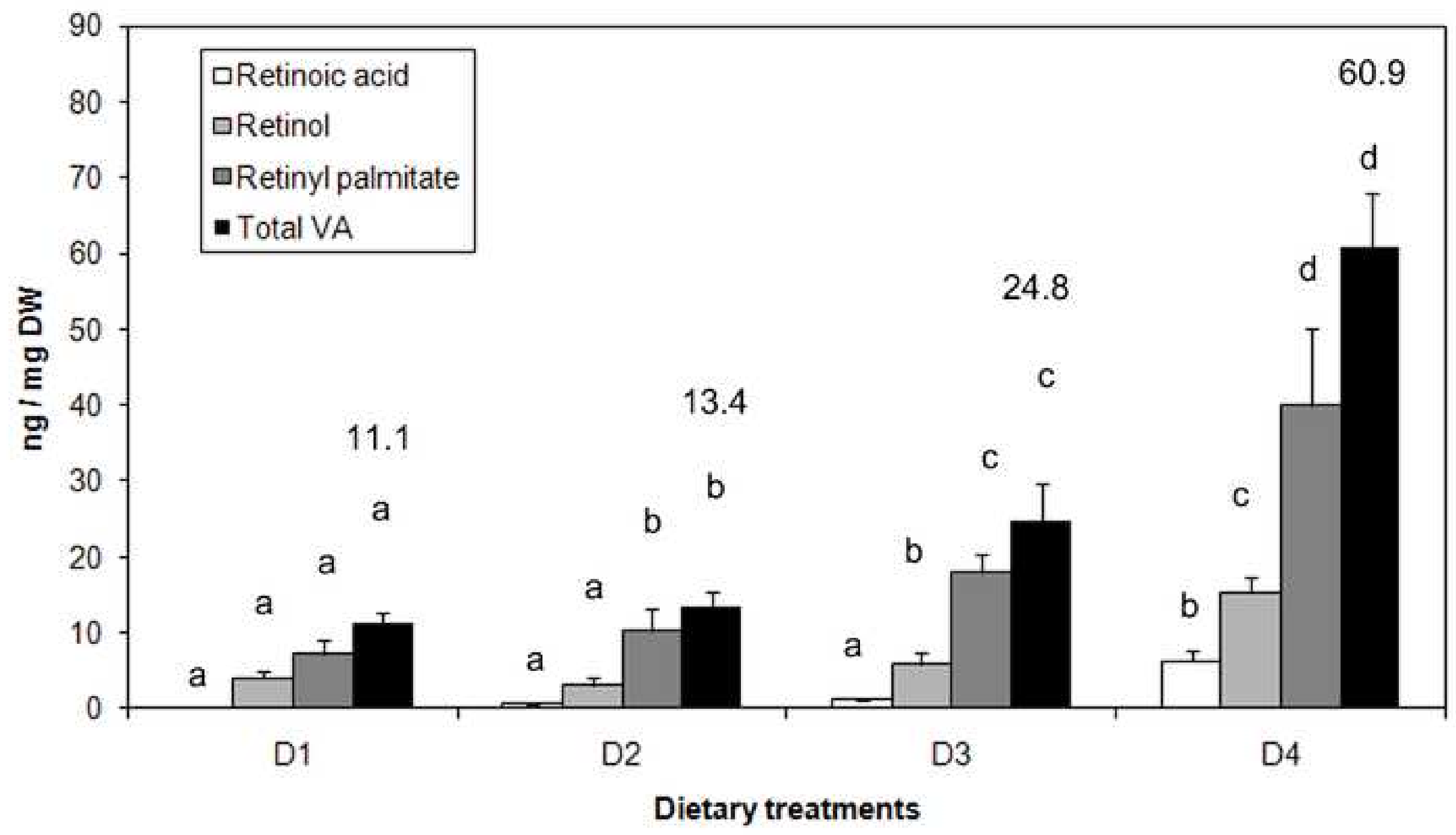


Figure 3

Click here to download high resolution image
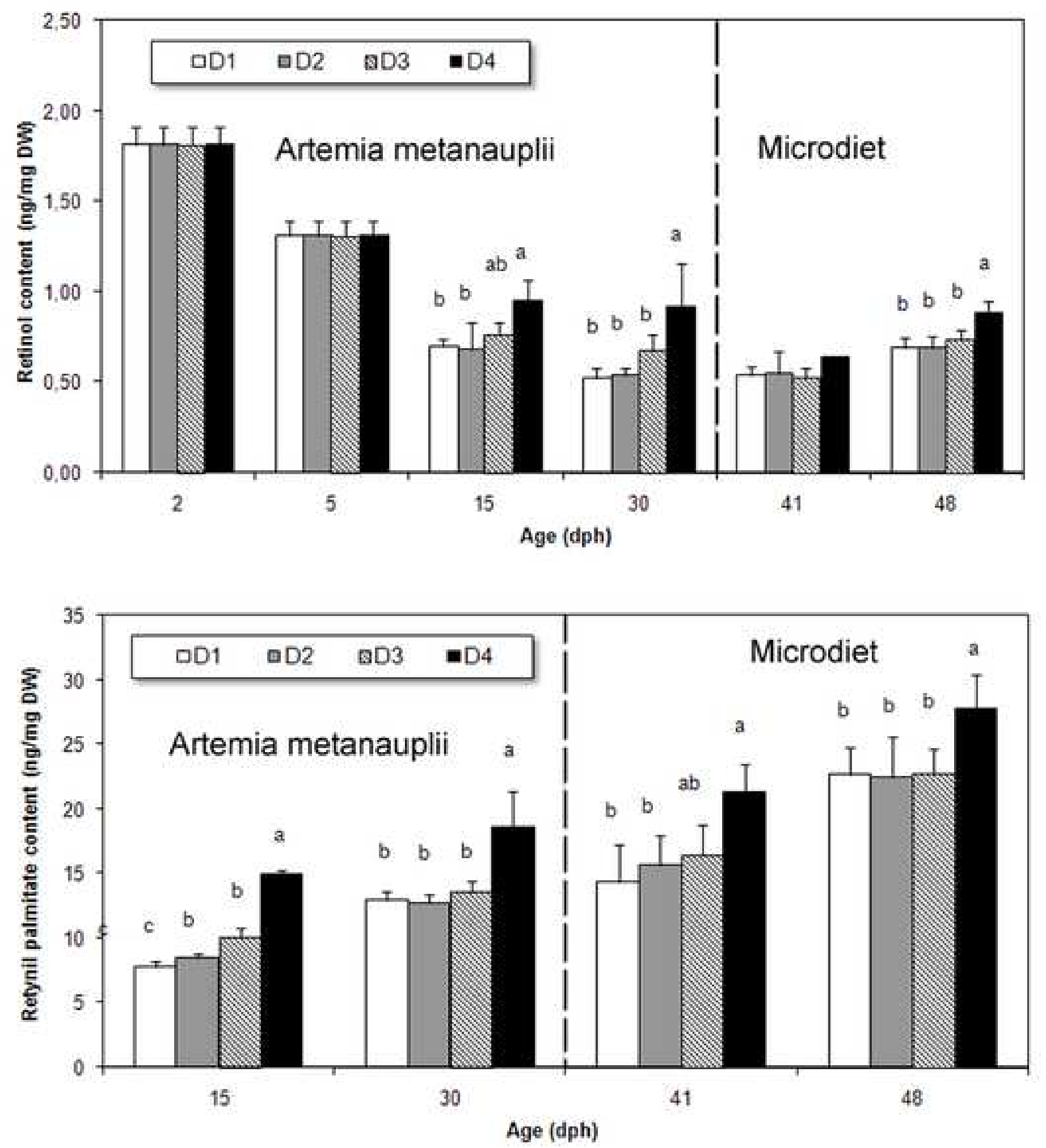
Figure 4
Click here to download high resolution image
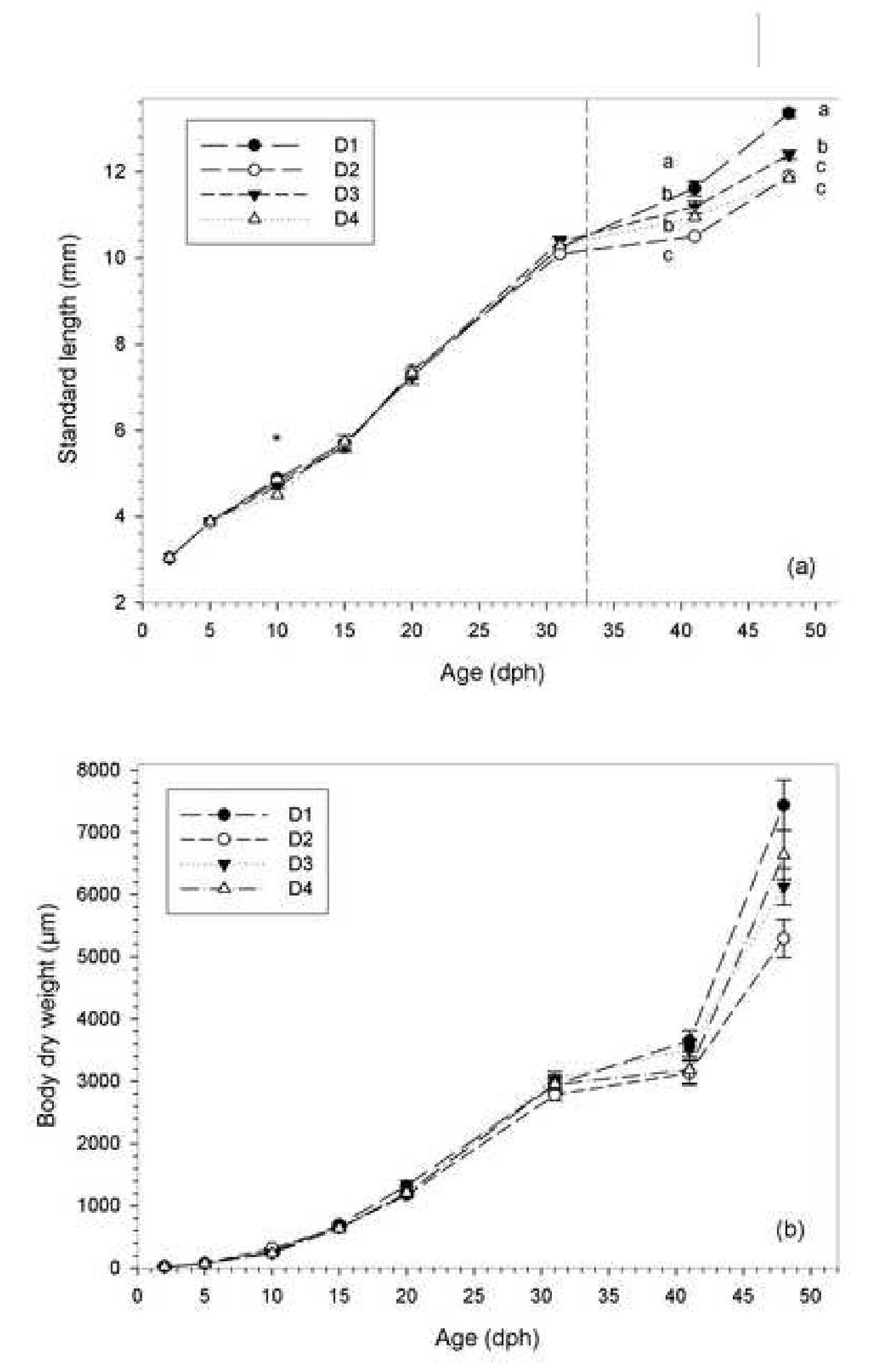

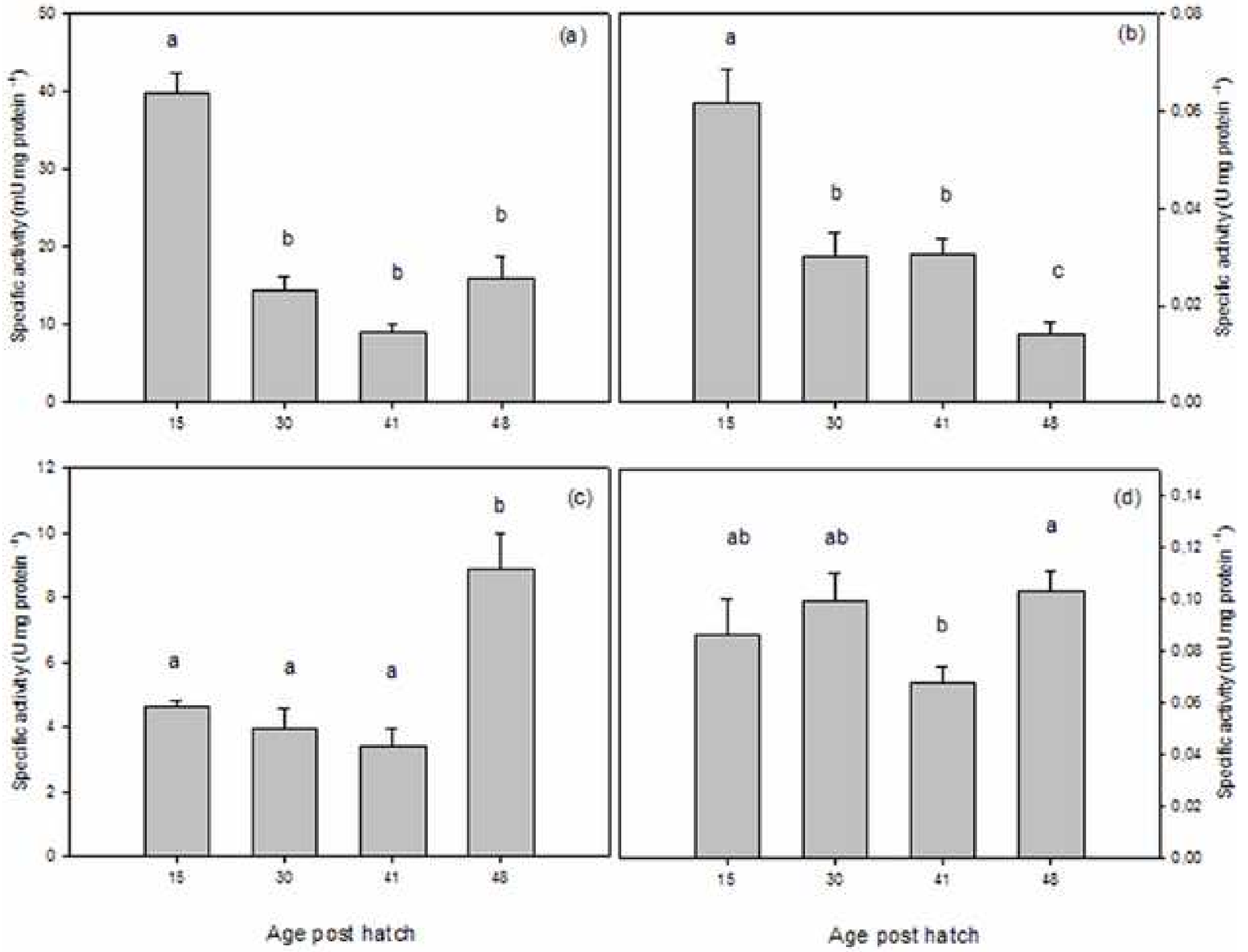


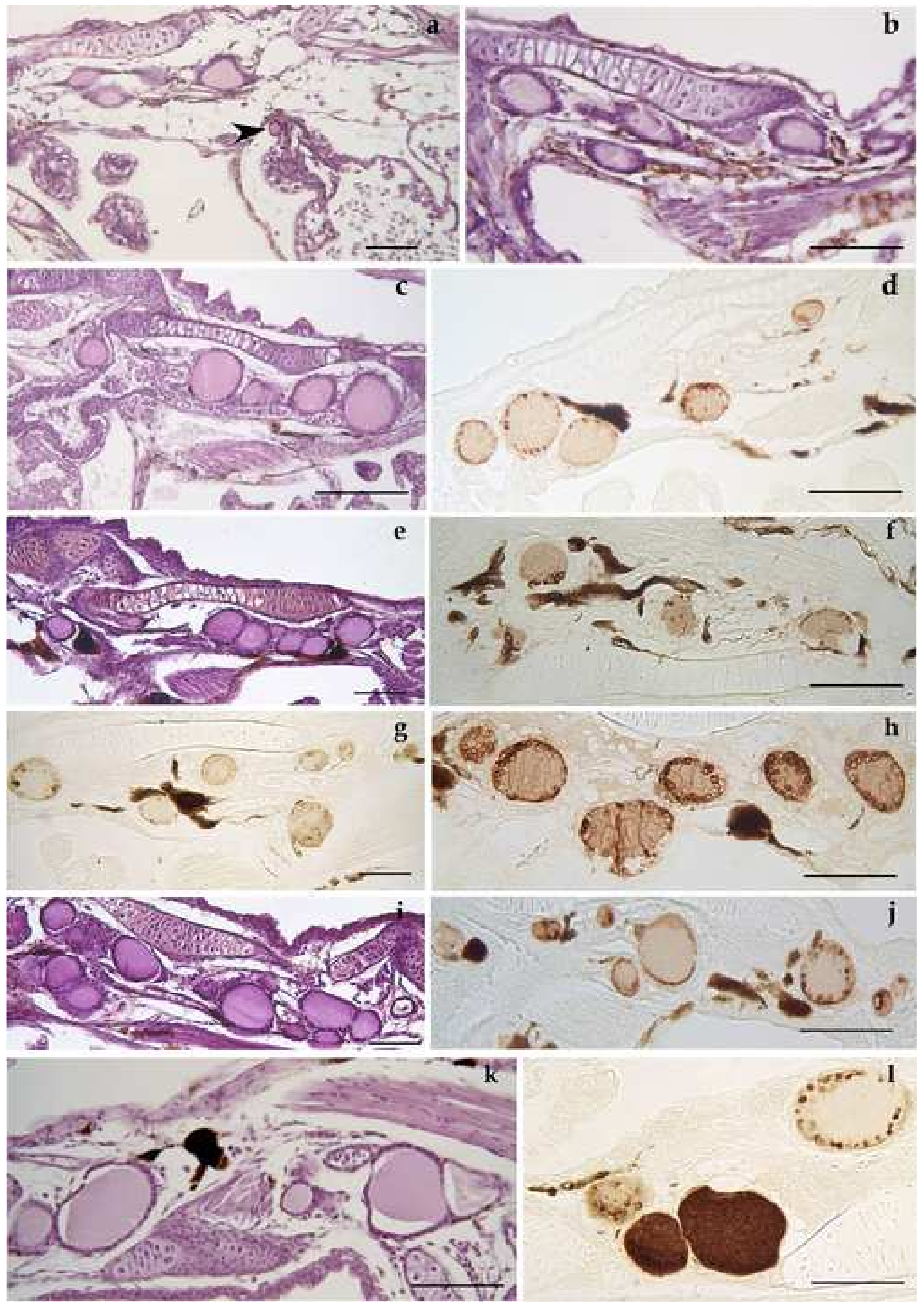



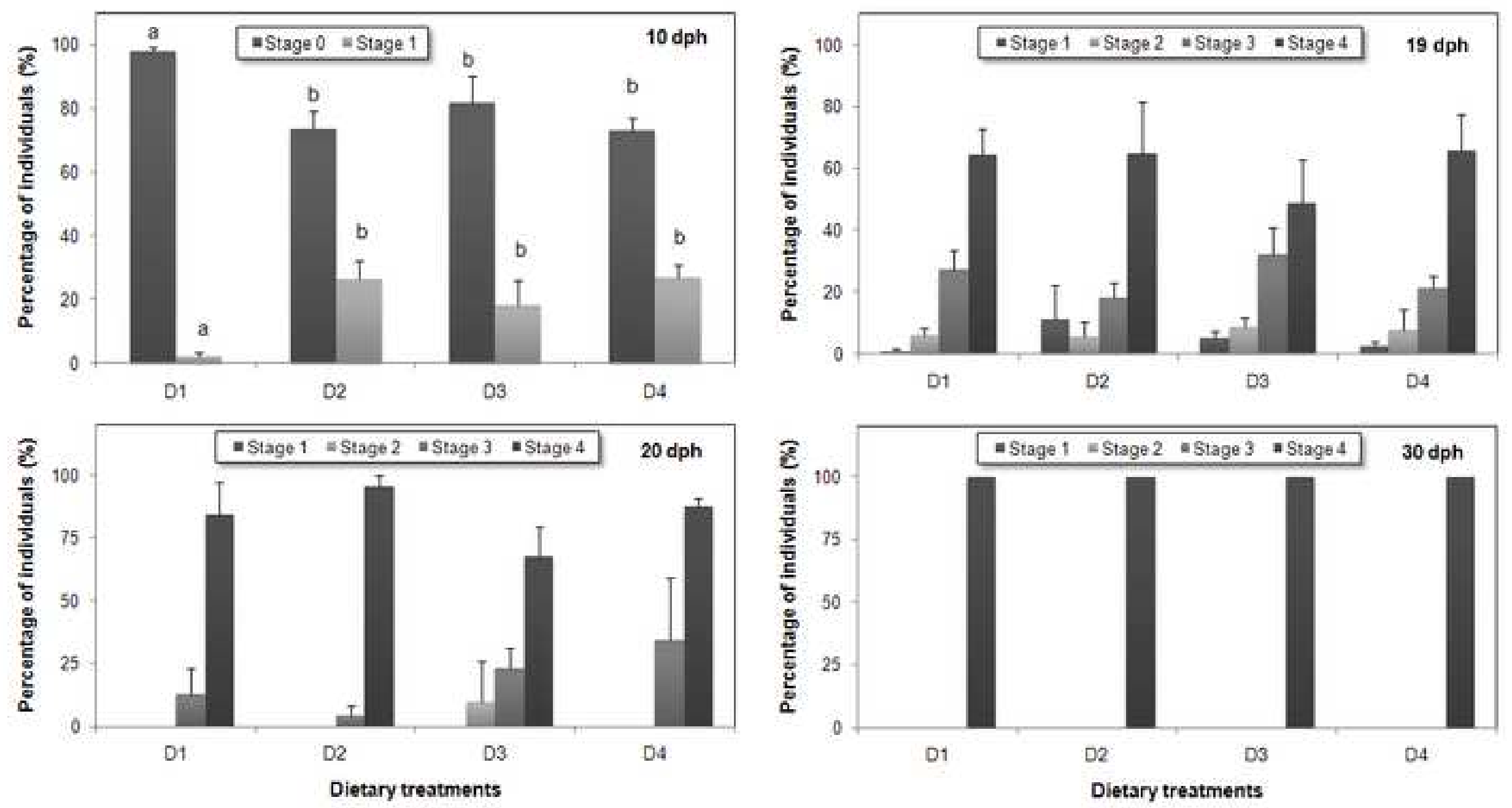
Figure 8

Click here to download high resolution image
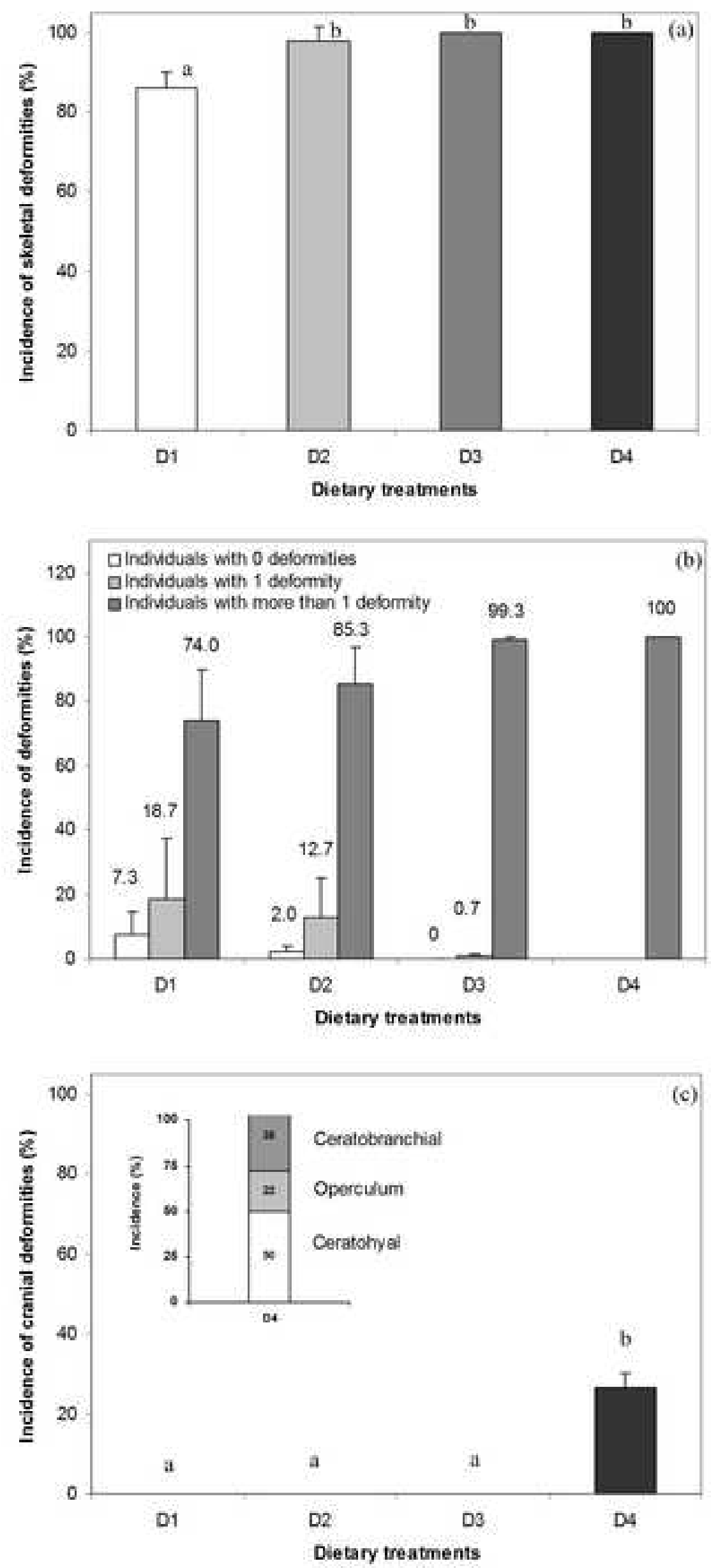

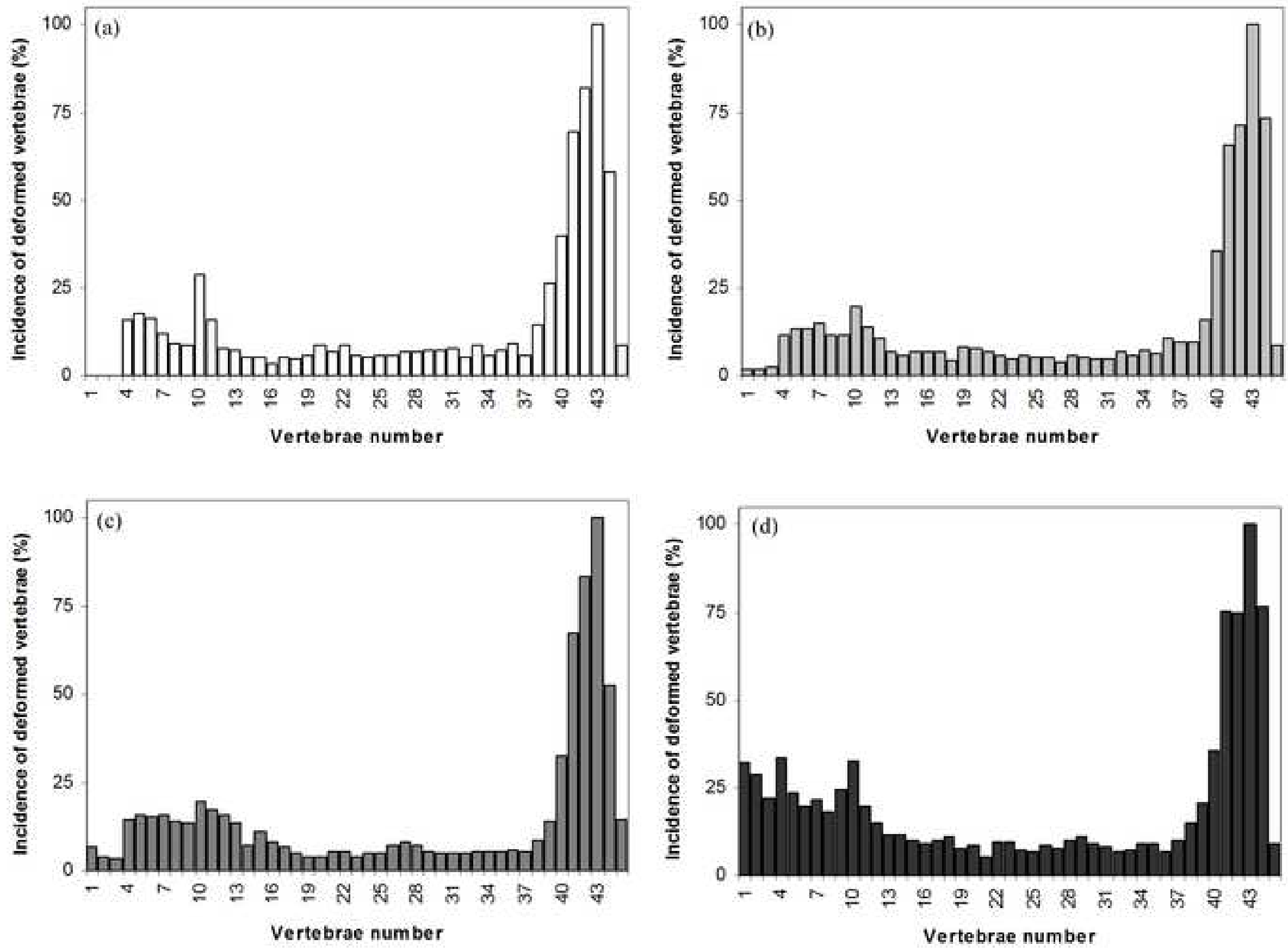

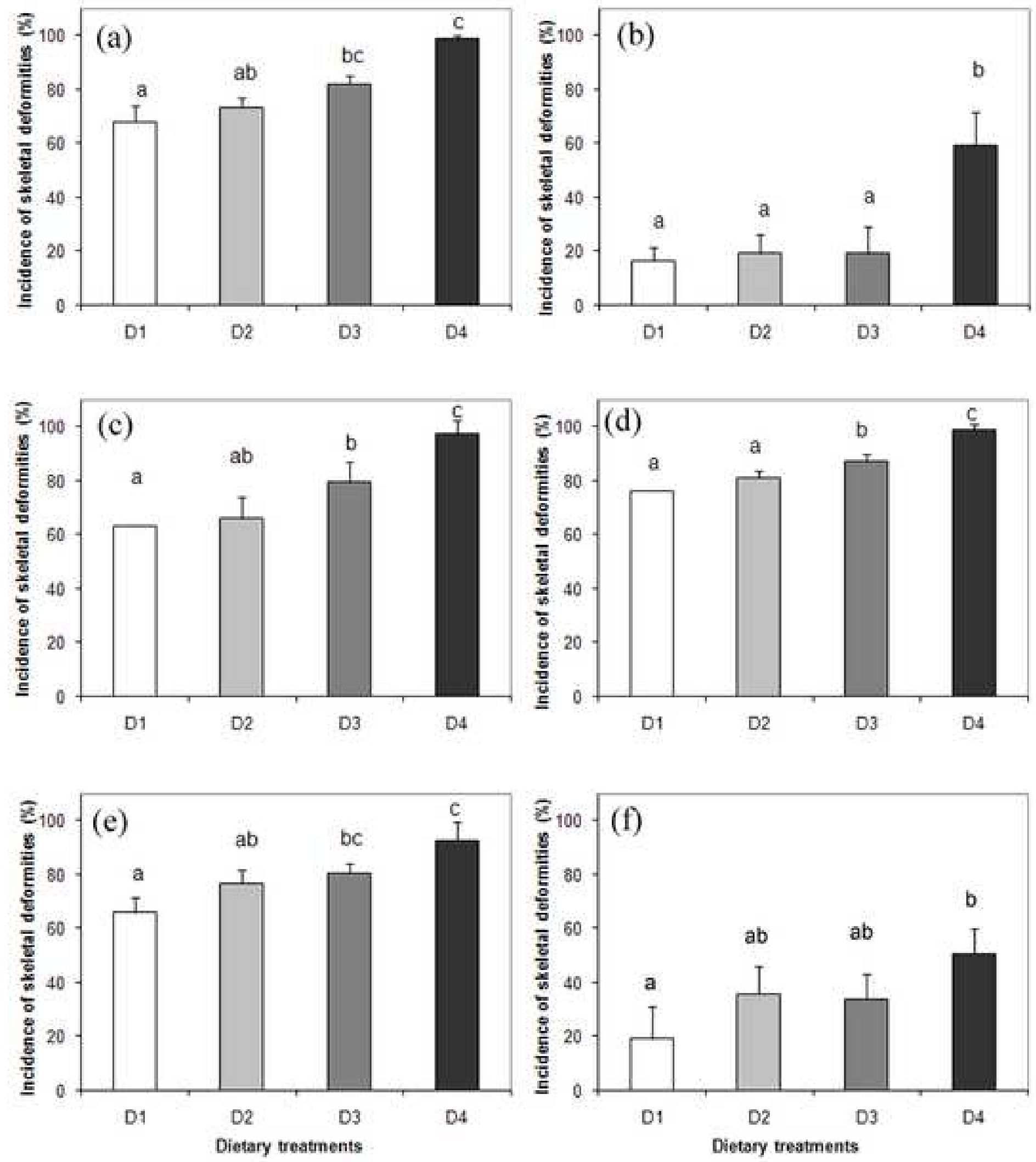

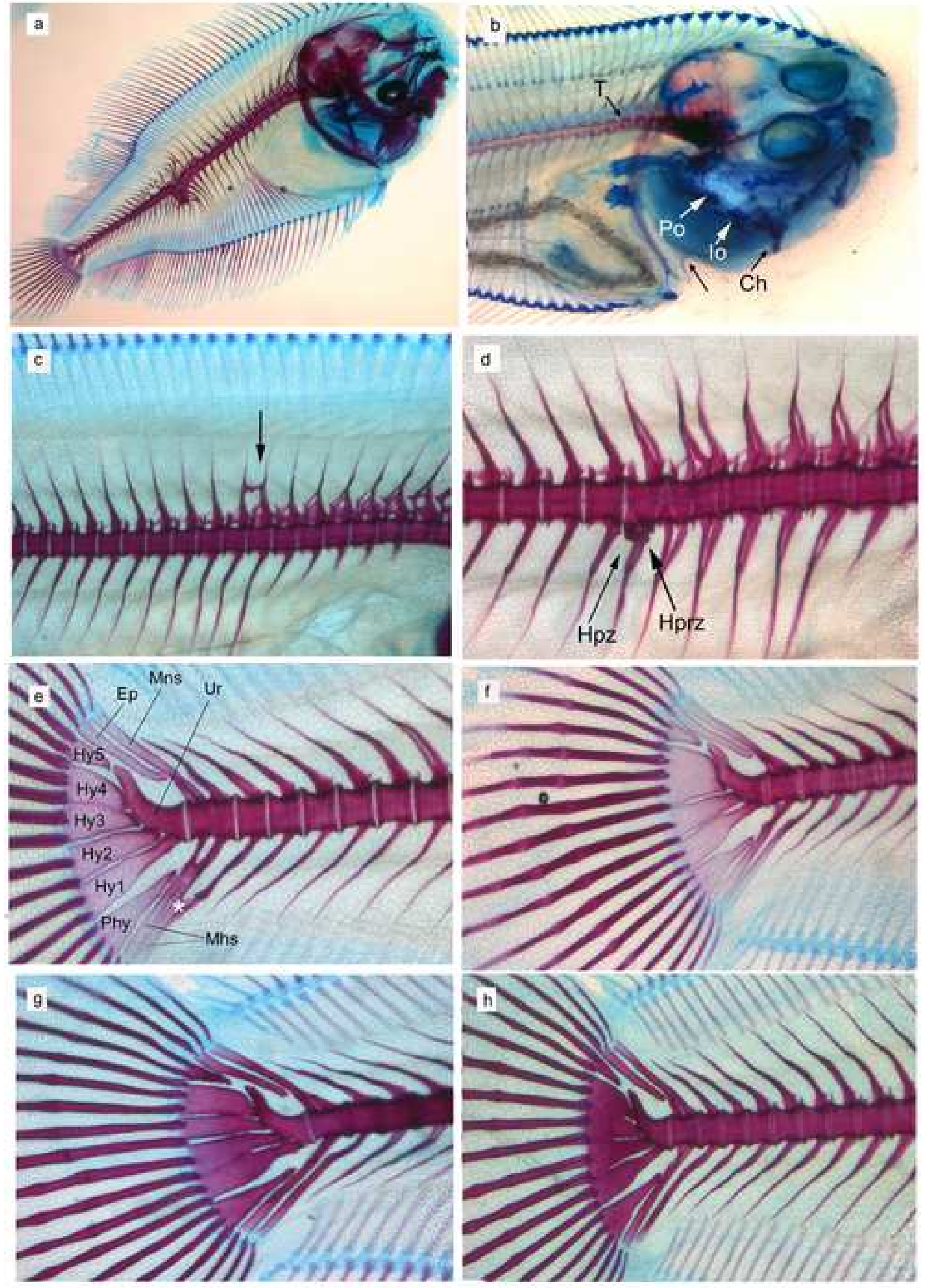

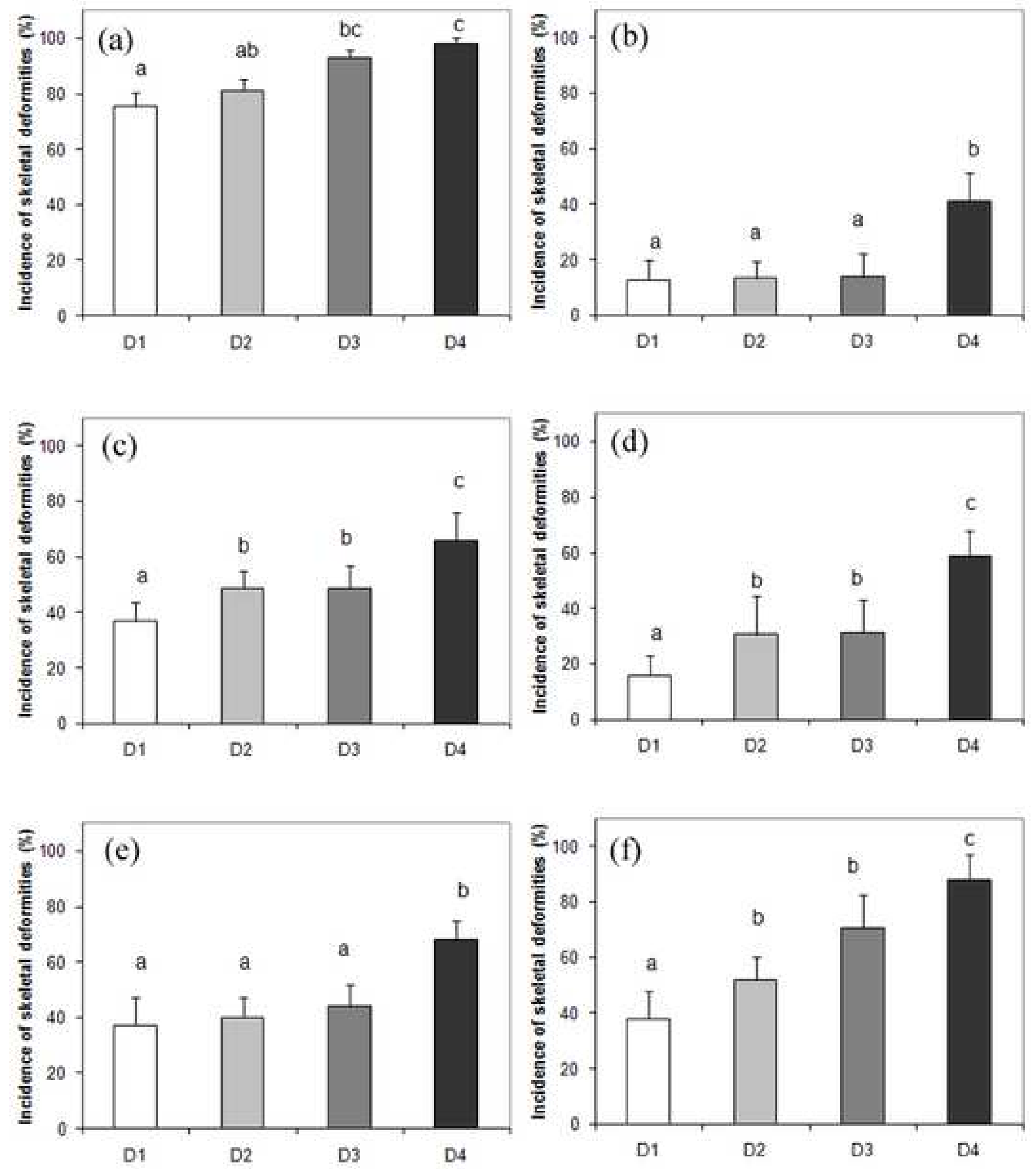